\title{
Influência do Ciclo Térmico de Soldagem no Crescimento de Grão, nas Transformações Microestruturais e na Formação de MA na GGZAC de aço TMCP*
}

\author{
Tadeu Messias Donizete Borba ${ }^{1}$, Paulo José Modenesi² \\ ${ }^{1}$ Centro de Pesquisa \& Desenvolvimento da Usiminas, Usiminas, Ipatinga, MG, Brasil. \\ ${ }^{2}$ Universidade Federal de Minas Gerais - UFMG, Departamento de Engenharia Metalúrgica e de Materiais, Belo Horizonte, MG, Brasil.
}

Como citar: Borba TMD, Modenesi PJ. Influência do ciclo térmico de soldagem no crescimento de grão, nas transformações microestruturais e na formação de MA na GGZAC de aço TMCP. Soldagem \& Inspeção. 2019;24:e2406. https://doi.org/10.1590/0104$9224 / \mathrm{SI} 24.06$

Resumo: A soldagem com elevado aporte térmico é uma das alternativas adotadas pelos estaleiros e fabricantes de torres eólicas para aumento da produtividade. No entanto, os ciclos térmicos gerados no processo podem provocar transformações microestruturais prejudiciais à tenacidade na zona afetada pelo calor, especialmente na região de grãos grosseiros (GGZAC). Neste trabalho foram avaliados o crescimento de grão e as alterações microestruturais na GGZAC de um aço de $355 \mathrm{MPa}$ de limite de escoamento produzido por laminação controlada seguida de resfriamento acelerado (TMCP - Thermomechanical Controlled Process) em comparação com um aço convencional de mesma classe de limite de escoamento. Condições de soldagem de elevado aporte térmico foram simuladas em dilatômetro e na Gleeble $^{\circledR}$. Foi observado que o tamanho de grão da austenita prévia na GGZAC segue uma distribuição log-normal e que o aço TMCP apresentou menores tamanhos de grão. Esse resultado foi associado ao efeito de ancoramento por precipitados de TiN homogeneamente distribuídos e coerentes com a matriz em regiões onde a máxima temperatura não é suficiente para a sua dissolução. Os resultados indicam que é possível obter excelente tenacidade a baixa temperatura em juntas soldadas com elevado aporte térmico quando empregado o aço TMCP.

Palavras-chave: GGZAC; Aços TMCP; Dilatometria; Gleeble ${ }^{\circledR}$; Elevado aporte térmico.

\section{Influence of Welding Thermal Cycle on Grain Growth, Microstructural Transformations and MA Formation on CGHAZ of TMCP Steel}

\begin{abstract}
High heat input welding is one of the alternatives adopted by shipyards and wind tower manufacturers for increasing productivity. However, the thermal cycles generated during welding may cause microstructural transformations that are detrimental to the toughness in the heat-affected zone, especially in the coarse-grained region (CGHAZ). In this work, the grain growth and the microstructural changes in the CGHAZ of $355 \mathrm{MPa}$ class steel, produced by controlled rolling followed by accelerated cooling - TMCP (Thermo-Mechanical-Control-Process) were compared to a conventional steel of the same grade. High heat inputs welding conditions were simulated in the dilatometer and Gleeble ${ }^{\circledR}$. It was observed that previous austenite grain size in the CGHAZ follows a log-normal distribution and the TMCP steel showed significantly lower values of grain size. This result was associated with pinning effect of TiN precipitates homogeneously distributed and coherent with the matrix in regions where the maximum temperature is not enough for its dissolution. The results showed that it is possible to obtain excellent toughness at low temperature in high heat input welded joints when using TMCP steel.
\end{abstract}

Key-words: CGHAZ; TMCP Steels; Dilatometry; Gleeble ${ }^{\circledR}$; High heat input welding.

\section{Introdução}

A procura por novas alternativas de geração de energia limpa e por meios de transportes mais eficientes, com menores emissões atmosféricas [1], tem sido o foco de grandes potências mundiais nos últimos anos. Nesse contexto a indústria eólica e a naval têm passado por processos de modernização dos seus meios de produção, objetivando a otimização dos custos e tempos de fabricação e redução do peso das estruturas e embarcações. Nesse cenário, os países asiáticos destacam-se como liderança mundial, sendo os maiores fabricantes de embarcações de grande porte e de torres eólicas [2,3]. Essa hegemonia se

*Este artigo foi selecionado para publicação dentre aqueles apresentados no XLIV CONSOLDA - Congresso Nacional de Soldagem Uberlândia, MG de 10 a 13 de Setembro de 2018. Recebido: 15 Fev., 2018 Aceito: 17 Mar., 2019.

E-mail: tadeu.borba@usiminas.com (TMDB) 
deve principalmente ao emprego de aços do tipo TMCP (Thermo Mechanical Control Process), pioneiramente desenvolvidos pelas siderúrgicas japonesas na década de 1970 [4]. Tais aços permitiram o aperfeiçoamento dos processos de união, dispensando a necessidade de preaquecimento na soldagem com baixo aporte térmico e viabilizando a exploração da soldagem com alto aporte térmico, resultando em um aumento da produtividade das etapas de soldagem durante a fabricação [5].

No Brasil, a indústria naval, após anos de estagnação, ressurgiu no início dos anos 2000 impulsionada pelos grandes investimentos realizados para o desenvolvimento da exploração em águas profundas do pré-sal. Nesse contexto, grandes estaleiros brasileiros, localizados nos estados do Rio de Janeiro, Pernambuco, Rio Grande do Sul, e Bahia [6], com o objetivo de otimizar os tempos e custos de produção, adquiriram equipamentos de soldagem capazes de realizar a soldagem com a deposição de um único passe de solda empregando aportes de calor da ordem de 200 a 280 kJ/cm. Segundo o SINAVAL [6], o Brasil possui 20 estaleiros de grande porte que, se não fosse o cenário politico/econômico atualmente desfavorável, esse setor teria capacidade de consumo de mais de 500 kt/ano, figura 1.

Já a geração de energia elétrica através da energia cinética dos ventos, só começou a ser explorada de forma expressiva no território brasileiro a partir de 2009, devido aos problemas de redução dos reservatórios hídricos o que impulsionou a criação de programas de incentivos federais como o PROINFA (Programa de Incentivo às Fontes Alternativas de Energia Elétrica) [7]. Segundo a ABEEOLICA (Associação Brasileira de Energia Eólica) [3], atualmente o Brasil possui em operação 583 parques eólicos com cerca de $7 \mathrm{mil}$ aerogeradores e uma capacidade instalada para a geração de14,7 GW/ano, representando mais de $9 \%$ da matriz energética brasileira. A maior geração de energia eólica se concentra nas regiões Nordeste e Sul, sendo o Rio Grande do Norte, Bahia, Ceará e Rio Grande do Sul os estados com maior capacidade instalada, Figura 1.

Apesar dos grandes investimentos para o desenvolvimento do setor eólico e naval nacional, ainda existem muitos problemas como falta de conhecimento e mão de obra qualificada, de desenvolvimento de novos materiais, de tecnologia e projetos modernos que otimizem as inúmeras operações de soldagem empregadas na fabricação dos aerogeradores e dos navios de grande porte.

Na literatura é possível encontrar trabalhos de P\&D e de aplicação [2,5,8-12] que comprovam a superioridade, principalmente em termos de soldabilidade, dos aços TMCP em relação aos aços convencionais. Porém, no Brasil, existem poucos trabalhos divulgando as vantagens de sua aplicação tanto na indústria naval quanto eólica nacional.

A simulação física dos ciclos térmicos é amplamente utilizada por institutos de pesquisa e empresas em várias partes do mundo em estudos de soldabilidade. Porém, devido ao reduzido número de equipamentos disponíveis no Brasil, existem poucos estudos nacionais que utilizaram essa metodologia [9-12]. Dessa forma, este estudo tem como principal objetivo avaliar o crescimento de grão, as alterações microestruturais e a tenacidade Charpy-V na região de grãos grosseiros da zona afetada pelo calor (GGZAC) de um aço TMCP de 355 MPa de limite de escoamento (LE), denominado UHHIW (Ultra High Heat Input Welding), em comparação com um aço de mesma classe de LE produzido por laminação convencional, ambos submetidos a distintos ciclos térmicos nos equipamentos dilatômetro e Gleeble ${ }^{\circledR}$, de forma a simular elevados aportes de soldagem.

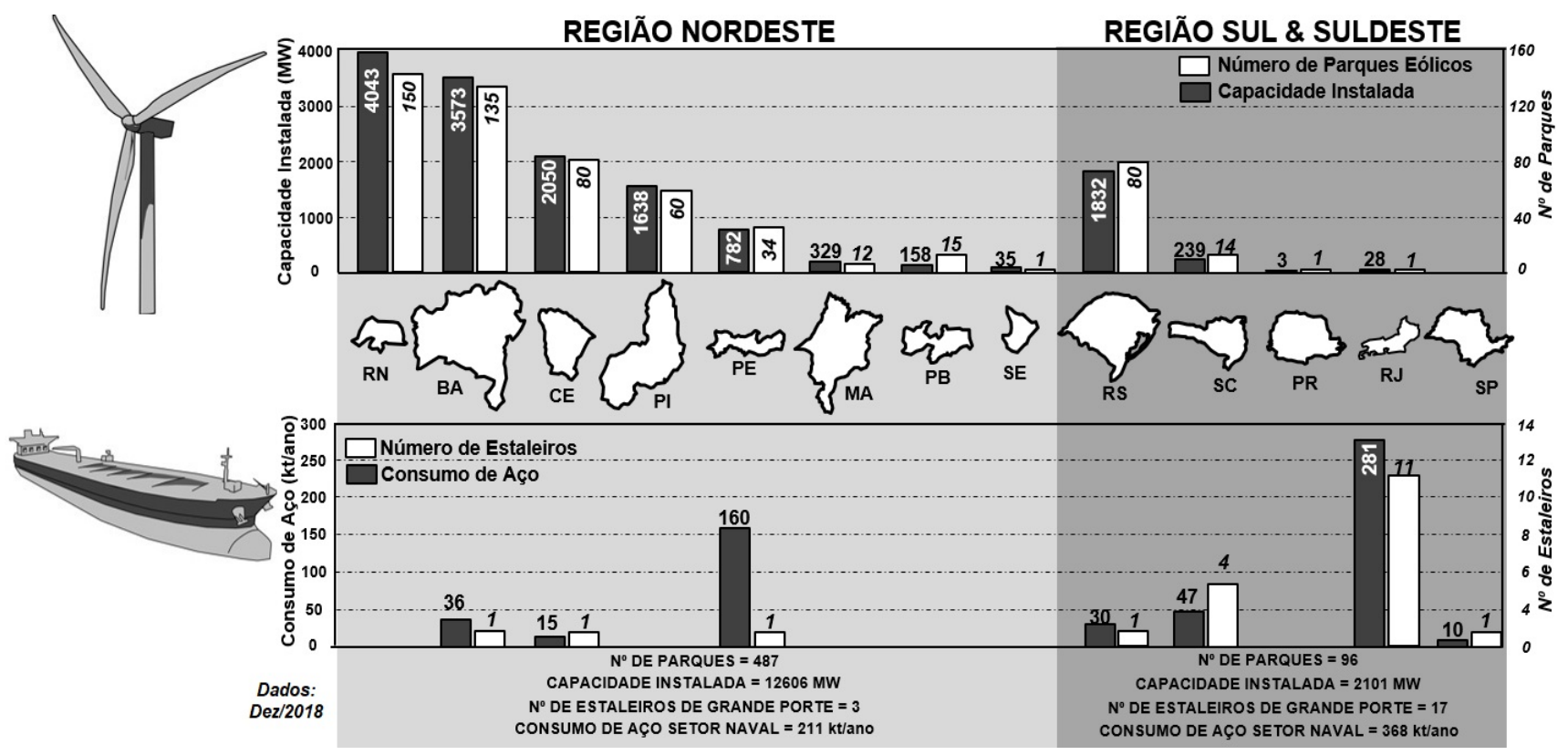

Figura 1. Setor naval e eólico segundo ABEEólica [3] e Sinaval [6]. Ilustração: Autor. 


\section{Materiais e Métodos}

\subsection{Materiais}

Neste estudo, foram avaliados os aços estruturais da classe de $355 \mathrm{MPa}$ de limite de escoamento, de $35 \mathrm{~mm}$ de espessura, produzidos em escala industrial e obtidos por dois métodos de processamento: (i) laminação controlada seguida de resfriamento acelerado (Aço Ultra High Heat Input Welding - UHHIW) e; (ii) laminação convencional seguida de tratamento térmico de normalização (Aço convencional - CONV). Ambos atendem os requisitos tanto da norma estrutural EN-10025 (CONV: parte 2; UHHIW: parte 4) [13,14] quanto do grau naval EH36 [1].

\subsubsection{Caracterização dos materiais}

(i) Análise Química: Para os dois materiais, foram retiradas amostras para a realização de análise química via espectroscopia ótica dos elementos, $\mathrm{Mn}, \mathrm{Si}, \mathrm{Al}, \mathrm{Ca}, \mathrm{Ni}, \mathrm{Cr}, \mathrm{Cu}, \mathrm{Nb}, \mathrm{V}$, Ti e P e via Leco ${ }^{\circledR}$ dos elementos C, S e N;

(ii) Avaliação Metalográfica Via Microscopia Ótica: Para cada material, foram retiradas amostras para realização das análises ao microscópio ótico, em seções contendo o plano de espessura e longitudinais ao sentido de laminação da chapa. Para a identificação dos constituintes presentes na matriz dos dois aços, foi realizado preparação metalográfica convencional e utilizado ataque químico com reagente nital $4 \%$. A análise do tamanho de grão ferrítico foi conduzida de acordo com a norma ASTM E112 [15].

(iii) Ensaios Mecânicos: foi realizado ensaio de tração para determinação do alongamento, do limite de escoamento e de resistência dos materiais estudados conforme os requisitos da norma ASTM A370 [16]. Também foi realizado perfil de dureza Vickers com carga de $5 \mathrm{kgf}$ ao longo de toda a espessura com espaçamento de $1 \mathrm{~mm}$ entre impressões. Além disso, foi realizado ensaio de impacto Charpy-V segundo a norma ASTM A370 [16] utilizando três CPs do tipo full size (10X10X55 mm) retirados no meio da espessura e sendo o seu comprimento paralelo a direção de laminação.

\subsection{Simulação do ciclo térmico de soldagem, caracterização metalográfica e ensaios de impacto Charpy-V}

Com o objetivo de desenvolver uma metodologia para a classificação e o desenvolvimento da engenharia de aplicação de aços produzidos por distintas rotas de fabricação em relação à soldabilidade, foram utilizados os equipamentos de simulação física dilatômetro e Gleeble ${ }^{\circledR}$ para a reprodução de diferentes ciclos térmicos de soldagem. Para tal, foi aplicada uma velocidade de aquecimento de $100^{\circ} \mathrm{C} / \mathrm{s}$ até a temperatura de $1350^{\circ} \mathrm{C}$, com tempo de permanência de dois segundos. Posteriormente os CPs foram resfriados com diferentes velocidades de resfriamento, conforme descrito na Tabela 1 . A correlação entre os diferentes tempos de resfriamento $\left(\Delta \mathrm{t} 8 / 5\right.$ - tempo em segundos de resfriamento entre $800^{\circ} \mathrm{C}$ e $\left.500^{\circ} \mathrm{C}\right)$ e os aportes térmicos (AT) simulados, foi determinada segundo as equações de Rykalin 2D (equação 1) [17].

$\eta \mathrm{AT}=\mathrm{h} \sqrt{\frac{4 \pi \mathrm{kc} \rho \Delta \mathrm{t}_{8 / 5}}{\frac{1}{\left(500-\mathrm{T}_{0}\right)^{2}}-\frac{1}{\left(800-\mathrm{T}_{0}\right)^{2}}}} \rightarrow \Delta_{\mathrm{t} 8 / 5}=\left(\frac{1}{4 \pi \mathrm{k} \rho \mathrm{c}}\right)\left(\frac{\eta \mathrm{AT}}{\mathrm{h}}\right)^{2}\left[\left(\frac{1}{500-\mathrm{T}_{0}}\right)^{2}-\left(\frac{1}{800-\mathrm{T}_{0}}\right)^{2}\right]$

Onde: $\mathrm{H}$ : Aporte Térmico $(\mathrm{J} / \mathrm{mm}) ; \eta$ : Rendimento térmico do processo de soldagem, que varia em função do processo de soldagem que, nesse caso, será considerado como igual a um; $\mathrm{k}$ : condutividade térmica $\left(0,5 \mathrm{~W} / \mathrm{cm}^{\circ} \mathrm{C}\right) ; \rho$ : densidade $\left(7,8 \mathrm{~g} / \mathrm{cm}^{3}\right)$; c: calor específico $\left(1 \mathrm{~J} / \mathrm{g}^{\circ} \mathrm{C}\right)$; Tp: temperatura máxima ou de pico $\left(1350^{\circ} \mathrm{C}\right)$; $\mathrm{T}_{0}$ : temperatura ambiente ou de preaquecimento $\left(25^{\circ} \mathrm{C}\right)$ e h: espessura da chapa ou peça $(3,5 \mathrm{~cm})$.

Tabela 1. Parâmetros utilizados para a simulação da GGZAC no equipamento dilatômetro.

\begin{tabular}{ccccccccccc}
\hline $\mathbf{\Delta} \mathbf{T}^{\circ} \mathbf{8} / \mathbf{5}\left({ }^{\circ} \mathbf{C} / \mathbf{s}\right)$ & $\mathbf{1 3 0}$ & $\mathbf{1 0 0}$ & $\mathbf{5 0}$ & $\mathbf{3 0}$ & $\mathbf{2 0}$ & $\mathbf{1 0}$ & $\mathbf{5 , 0}$ & $\mathbf{2 , 0}$ & $\mathbf{1 , 0}$ & $\mathbf{0 , 5}$ \\
$\mathbf{t} \mathbf{8} / \mathbf{5}(\mathbf{s})$ & 2 & 3 & 6 & 10 & 15 & 30 & 70 & 150 & 300 & 500 \\
$\mathbf{A T}(\mathbf{k J} / \mathbf{c m})$ & 4 & 5 & 12 & 50 & 60 & 80 & 120 & 180 & 250 & 330 \\
\hline
\end{tabular}

$\Delta T^{\circ} 8 / 5=$ Velocidade de resfriamento entre $800^{\circ} \mathrm{C}$ e $500^{\circ} \mathrm{C} ; \mathrm{t} 8 / 5=$ Tempo de resfriamento entre $800^{\circ} \mathrm{C}$ e $500^{\circ} \mathrm{C} ; \mathrm{AT}=$ Aporte Térmico. 


\subsubsection{Ensaios dilatométricos}

A avaliação do efeito dos ciclos térmicos nas temperaturas de transformação da GGZAC dos aços em questão foi realizada através de ensaios dilatométricos, simulando aportes térmicos de soldagem compreendendo valores entre 4 e $330 \mathrm{~kJ} / \mathrm{cm}$, Tabela 1. A análise por dilatometria é uma das técnicas de simulação termomecânica mais utilizadas para o estudo das transformações de fase no estado sólido em condições isotérmicas, de aquecimento contínuo e de resfriamento contínuo [18-20]. Esta técnica permite determinar a evolução microestrutural em relação ao binômio tempo/temperatura através de alterações dimensionais do CP quando submetido a um ciclo térmico específico. A avaliação das alterações dimensionais e microestruturais do CP são utilizados para determinar as temperaturas críticas de transformação de um determinado material [21].

Foram utilizados corpos de prova (CPs) cilíndricos com $4 \mathrm{~mm}$ de diâmetro e $10 \mathrm{~mm}$ de comprimento, com o maior eixo orientado paralelamente à direção de laminação. Em todos os CPs submetidos aos ensaios dilatométricos, realizou-se, qualitativamente, através de uma malha de 16 pontos aplicada em cinco distintas regiões, a caracterização metalográfica via microscopia ótica (MO) após ataque com nital $4 \%$ seguindo a classificação do The Welding Institute (TWI) [22], Tabela 2. Nesta mesma seção, realizaram-se ensaios de dureza Vickers com carga de 5 kgf.

\subsubsection{Simulação do maior aporte térmico na Gleeble ${ }^{\circledR}$}

Uma vez que as dimensões dos CPs utilizados no equipamento dilatômetro não permitem a realização de ensaios mecânicos, foi realizada a simulação do ciclo térmico de $0,5 \circ \mathrm{C} / \mathrm{s}\left(\mathrm{AT}=330 \mathrm{~kJ} / \mathrm{cm}\right.$ ) via equipamento Gleeble ${ }^{\circledR}$, conforme esquematicamente ilustrado na Figura 2, para avaliar o efeito desse elevado aporte de calor, considerado, nesse trabalho, como o mais crítico para o crescimento de grão na GGZAC e na tenacidade da GGZAC resultante. Para cada aço avaliado, foram utilizados 5 CPs de seção quadrada 10 x 10 mm e 105 mm de comprimento, amostrados longitudinalmente em relação à direção de laminação e realizadas as seguintes análises:

(i) Análise Metalográfica: quantificação dos microconstituintes via $\mathrm{MO}$ e após ataque com nital 4\%, através do método do intercepto, segundo a norma ASTM E 562-89 [23]. Utilizou-se uma malha de 25 pontos para um aumento de 200X. Calculou-se um intervalo de confiança de $95 \%$ para os valores de fração volumétrica de cada microconstituinte. Para cada amostra, foram realizadas 100 aplicações da malha, resultando na contagem de 2500 pontos por amostra. Os microconstituintes foram classificados conforme o sistema criado pelo The Welding Institute-TWI [22], Tabela 2;

(ii) Determinação da Área do Grão Austenítico Prévio (TGү): via análise de imagens utilizando o software ImageJ, usando como referência os grãos de ferrita proeutetóide formadas nos contornos de grão de austenita. O objetivo é correlacionar o TGy com os resultados de tenacidade Charpy - V;

(iii) Quantificação do constituinte MA: via análise de imagens utilizando o software ImageJ, após ataque combinado dos reagentes picral e metabissulfito de sódio. O objetivo é correlacionar a presença de MA com os resultados de tenacidade Charpy - V e;

(iv) Ensaios de Impacto Charpy-V: para cada aço, foram ensaiados 4 CPs a $-40 \circ \mathrm{C}$ (temperatura especificada para os aços avaliados na condição mais crítica estipulada para o grau naval EH36) conforme a norma ASTM A370 [16]. Os CPs foram redimensionados para o tipo full size $(10 \times 10 \times 55 \mathrm{~mm})$, com o entalhe posicionado logo abaixo da região do termopar, Figura 2.

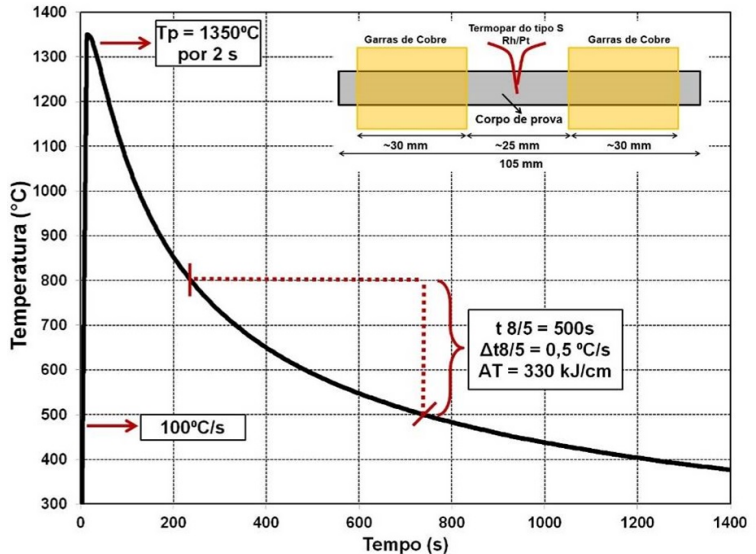

(a) Ciclo térmico simulado.

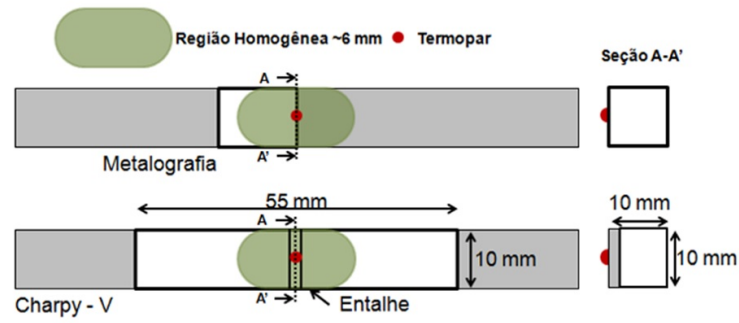

(b) Corpos de prova utilizados.

Figura 2. Ilustração esquemática dos ciclos térmicos e dos CPs simulados na Gleeble ${ }^{\circledR}$. 
Tabela 2. Classificação dos diferentes produtos de transformação da austenita na ZAC. Adaptado de [12,22].

\begin{tabular}{|c|c|c|c|}
\hline 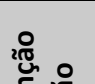 & "The Welding Institute" & $\begin{array}{l}\text { Terminologia adotada por outros } \\
\text { Pesquisadores }\end{array}$ & Descrição Geral \\
\hline 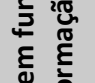 & Ferrita Proeutetóide - FP & $\begin{array}{l}\text { Ferrita de contorno de grão - FC } \\
\text { Ferrita poligonal intragranular - FPI }\end{array}$ & $\begin{array}{l}\text { Grãos alotriomórficos formados no contorno da y; } \\
\text { Grãos poligonais ou equiaxiais; }\end{array}$ \\
\hline 岕 & Perlita - P & $\begin{array}{c}\text { Perlita - P } \\
\text { Agregado Ferrita Carboneto - AFC }\end{array}$ & Estrutura lamelar constituída de ferrita e cementita \\
\hline 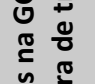 & $\begin{array}{l}\text { Ferrita com MAC Alinhada - } \\
\text { FSA }\end{array}$ & $\begin{array}{l}\text { Ferrita de Widmanstätten - FW Bainita } \\
\text { Superior - BS }\end{array}$ & $\begin{array}{l}\text { Placas paralelas de ferritas que tem suas origens em } \\
\text { FPI ou FC Ex:(Ferrita de Widmannstätten); }\end{array}$ \\
\hline 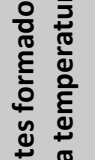 & $\begin{array}{l}\text { Ferrita com MAC Não Alinhada - } \\
\text { FSN }\end{array}$ & $\begin{array}{l}\text { Estrutura Granular - EG } \\
\text { Bainita Inferior - BI }\end{array}$ & $\begin{array}{c}\text { Placas de ferritas cercadas por microfases } \\
\text { aproximadamente equiaxiais sem orientação } \\
\text { definida ou somente agulhas de ferritas sem } \\
\text { orientação definida; }\end{array}$ \\
\hline 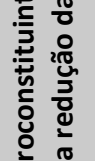 & $\begin{array}{l}\text { Ferrita de Widmanstätten } \\
\text { Intragranular - FWI }\end{array}$ & Ferrita Acicular - FA & $\begin{array}{l}\text { Microconstituinte formado no interior do grão } \gamma \text {, } \\
\text { com aspecto de finas agulhas de orientação não } \\
\text { definida separadas por contornos de alto ângulo e } \\
\text { com razão de aspecto de } 3: 1\end{array}$ \\
\hline$\underbrace{\overline{\underline{z}}}$ & Martensita - M & $\begin{array}{c}\text { Martensita - M } \\
\text { Bainita Inferior - BI }\end{array}$ & Martensita lenticular ou em placas \\
\hline
\end{tabular}

\section{Resultados e Discussão}

\subsection{Caracterização dos materiais base}

Na Figura 3, podem ser observados os aspectos microestruturais dos materiais em questão. O aço CONV apresenta um bandeamento microestrutural de ferrita poligonal e perlita. No caso do aço UHHIW percebe-se a presença, em maior quantidade, de ferrita poligonal e bainita e, em menor quantidade, de finos nódulos de perlita, mais refinados do que os microconstituintes observados no aço CONV. Na figura 3c é evidenciado que o aço UHHIW apresenta, em maior quantidade, ferrita poligonal (67\%) e bainita (29\%) e, em menor quantidade, perlita (4\%). Já para o aço CONV observa-se a predominância de ferrita poligonal (68\%) em relação a perlita (32\%). Por fim, na figura $3 \mathrm{~d}$ é apresentado a distribuição de tamanho de grão ferrítico, realizado conforme a norma ASTM E112 [15], comprovando, quantitativamente, que o aço UHHIW apresenta uma microestrutura mais refinada (10 $\pm 1 \mu \mathrm{m} ; \mathrm{n}=112)$ em relação ao aço CONV (19 $\pm 2 \mu \mathrm{m} ; \mathrm{n}=112)$. O refinamento microestrutural do aço UHHIW é atribuído ao efeito combinado dos parâmetros de laminação controlada e do resfriamento acelerado que, associados à composição química, afetam significativamente os produtos de transformação da austenita.

O refinamento microestrutural do aço UHHIW pode ser atribuído ao efeito combinado dos parâmetros de laminação controlada e do resfriamento acelerado que, associados à composição química, afetam significativamente os produtos de transformação da austenita. Como já foi demonstrado em diversos trabalhos [2,5,8-12,24,25], esse refinamento estrutural proporciona uma excelente combinação de resistência mecânica com elevados valores de tenacidade. A composição química realizada via espectroscopia ótica, e as propriedades mecânicas e tenacidade Charpy-V desses materiais se encontram nas Tabelas 3 e 4, respectivamente.

Tabela 3. Composição química dos aços UHHIW e CONV (\% p/p).

\begin{tabular}{|c|c|c|c|c|c|c|c|}
\hline Aço & C & Mn & $\mathbf{S i}$ & $\mathbf{P}$ & $\mathbf{S}$ & Al & $\mathrm{Ca}$ \\
\hline UHHIW & 0,09 & 1,38 & 0,22 & 0,012 & 0,0009 & 0,033 & 0,0016 \\
\hline CONV & 0,16 & 1,42 & 0,18 & 0,020 & 0,0020 & 0,035 & 0,0021 \\
\hline \multicolumn{3}{|c|}{$\mathrm{Ni}+\mathrm{Cr}+\mathrm{Cu}+\mathrm{Nb}+\mathrm{V}$} & $\mathrm{Ti}$ & $\mathbf{N}$ & $\mathrm{Ti} / \mathrm{N}$ & $\mathrm{Ceq}^{(\mathrm{a})}$ & $\mathrm{Pcm}^{(b)}$ \\
\hline UHHIW & \multicolumn{2}{|c|}{0,095} & 0,010 & 0,0042 & 2,37 & 0,32 & 0,17 \\
\hline CONV & \multicolumn{2}{|c|}{0,11} & 0,020 & 0,0039 & 5,13 & 0,41 & 0,24 \\
\hline
\end{tabular}

Nota: $\mathrm{Ceq}^{(a)}=\mathrm{C}+\mathrm{Mn} / 6+(\mathrm{Ni}+\mathrm{Cu}) / 15+(\mathrm{Cr}+\mathrm{Mo}+\mathrm{V}) / 5[26] ; \mathrm{Pcm}{ }^{(b)}=\mathrm{C}+\mathrm{Si} / 30+(\mathrm{Mn}+\mathrm{Cu}+\mathrm{Cr}) / 20+\mathrm{Ni} / 60+\mathrm{Mo} / 15+\mathrm{V} / 10+5 B[26]$. 
Tabela 4. Valores de propriedades mecânicas e tenacidade Charpy-V dos aços UHHIW e CONV.

\begin{tabular}{|c|c|c|c|}
\hline Aço & Limite de Escoamento (MPa) ${ }^{\mathrm{a}}$ & Limite de Resistência (MPa) ${ }^{a}$ & Alongamento (\%) \\
\hline UHHIW & $408 \pm 6$ & $513 \pm 8$ & $31 \pm 2$ \\
\hline CONV & $416 \pm 3$ & $541 \pm 7$ & $23 \pm 3$ \\
\hline Espec. EN10025 (2\&4) & $\geq 345$ & $470-630$ & $\geq 21$ \\
\hline Espec. EH 36 & $\geq 345$ & $490-620$ & $\geq 15$ \\
\hline \multirow{2}{*}{ Aço } & \multirow{2}{*}{$\begin{array}{c}\text { Charpy-V }(J)^{c} \\
\left(-40^{\circ} \mathrm{C}\right)\end{array}$} & \multicolumn{2}{|c|}{ Especificação } \\
\hline & & EN10025 (2\&4) & EH 36 \\
\hline UHHIW & $433 \pm 2$ & $31 \mathrm{~J}(-40 \div \mathrm{C})$ & \multirow{2}{*}{$34 \mathrm{~J}\left(-40^{\circ} \mathrm{C}\right)$} \\
\hline CONV & $147 \pm 39$ & $27 \mathrm{~J}(-20 \circ \mathrm{C})$ & \\
\hline
\end{tabular}

Nota: a - valor médio determinado a partir do ensaio de três corpos de prova; b - Base de Medida = 50 mm; c - valor médio determinado a partir do ensaio de cinco corpos de prova ensaiados na temperatura de -40 으.

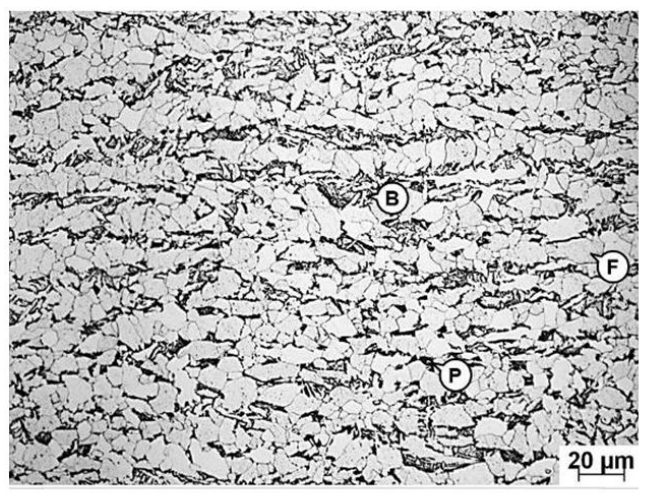

(a) Aço UHHIW.

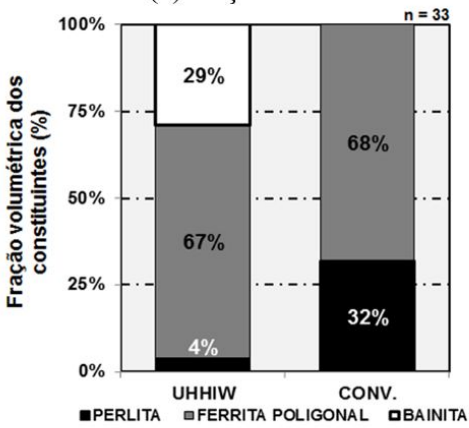

(c) Distribuição do tamanho de grão ferrítico.

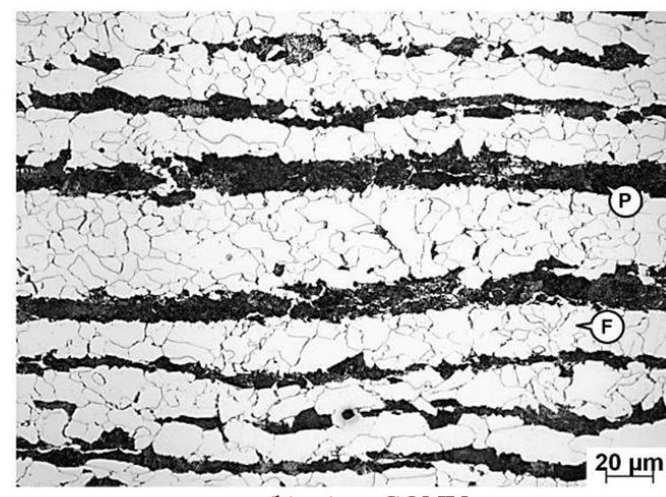

(b) Aço CONV.

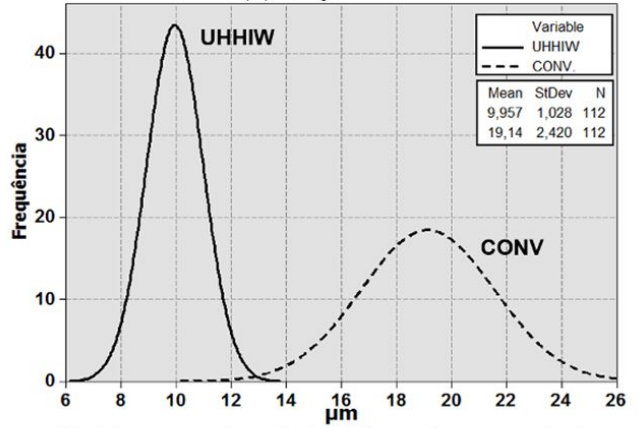

(d) Fração volumétrica dos microconstituintes.

Figura 3. Microestrutura, distribuição do tamanho de grão ferrítico e fração volumétrica dos microconstituintes dos aços avaliados. Ataque: Nital 4\%. B = Bainita; F = Ferrita; $P$ = Perlita.

\subsection{Simulação dos ciclos térmicos de soldagem via ensaios dilatométricos}

Na literatura é possível encontrar diversos diagramas de transformação no resfriamento contínuo (Contínuous Cooling Transformation - CCT) que descrevem as transformações de fases durante processos de tratamento térmicos de aços porém, poucos desses são de fato aplicáveis aos estudos voltados para a ZAC devido: (i) as lentas velocidades de aquecimento utilizadas, geralmente menores que $5 \circ \mathrm{C} / \mathrm{s}$, e; (ii) manipulação de amostras com tamanho de grão austenítico menores do que os normalmente observados na GGZAC devido, basicamente, as baixas temperaturas de pico ou de austenitização empregadas nesse tipo de abordagem. Dessa forma, na figura 4 é apresentado o efeito da velocidade de aquecimento nas temperaturas de transformação $A_{c 1}$ e Acs. É notório o aumento das temperaturas de transformação com o aumento da velocidade de aquecimento. O aumento da velocidade de aquecimento afeta os mecanismos difusionais elevando as temperaturas de transformação, especialmente a temperatura final de austenitização, Acз. Na Figura $4 \mathrm{~b}$ observa-se que a continua expansão do CP com o aumento da temperatura é alterada para contração quando este atinge a temperatura de início de austenitização, $\mathrm{Ac}_{1}$, que ocorre devido a variação do fator de empacotamento entre as células CCC e CFC formada [27]. A seta vermelha nas curvas da deriva temporal dos aços marca o início da decomposição da ferrita proeutetóide e o término da decomposição da 
perlita (p), no caso do aço CONV, e da bainita/perlita (p/B) no caso do aço UHHIW, em austenita [28]. A partir desse ponto (após a finalização da decomposição da perlita), a austenita continua sendo formada, porém exclusivamente as custas da decomposição da ferrita em um processo que, segundo a literatura, é mais lento do que o anterior [29].
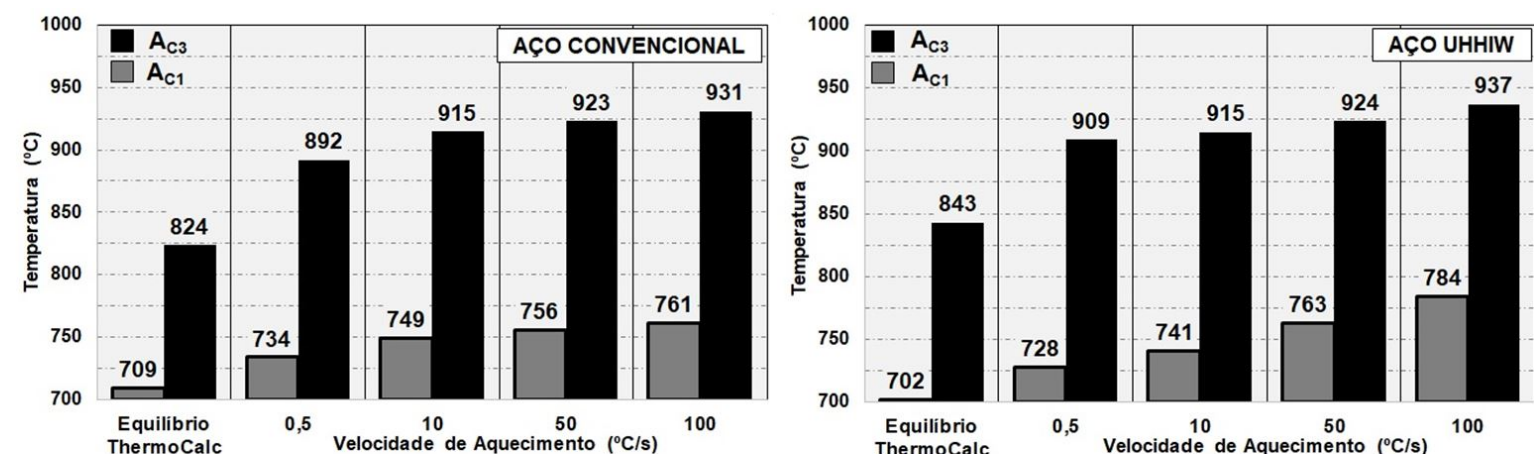

(a) Variação da temperatura de transformação em relação a velocidade de aquecimento.
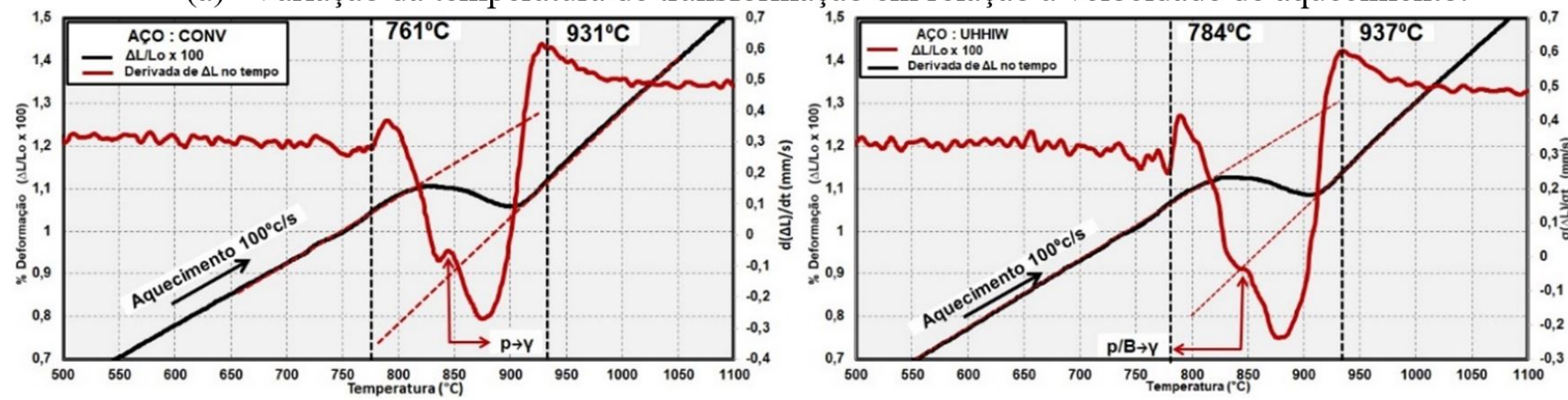

(b) Curvas dilatométricas obtidas durante o aquecimento com velocidade de $100^{\circ} \mathrm{C} / \mathrm{s}$.

Figura 4. Variação das temperaturas de início e fim de austenitização em relação a velocidade de aquecimento.

As microestruturas identificadas em algumas condições de baixa e alta velocidade de resfriamento são apresentadas na Figura 5. Para as condições de baixa velocidade de resfriamento, a análise metalográfica qualitativa, figura 6, revelou diferentes proporções dos mesmos microconstituintes entre os aços avaliados. Observa-se a ferrita de contorno de grão (FC) e, em algumas regiões, pequenos nódulos de perlita $(P)$ nos contornos de grãos da austenita prévia (CG $\gamma$ ), e ferrita com segunda fase alinhada (FSA) e não alinhada (FSN) e ferrita poligonal (FPI) no interior dos grãos. É evidente que as microestruturas do aço UHHIW são mais grosseiras que os microconstituintes do aço CONV, o que está relacionado com o início de transformação em temperaturas mais elevadas em relação ao aço CONV, como será evidenciado na figura 7. No caso do aço CONV observa-se uma maior quantidade de segunda fase entre as ripas das FSA e FSN, o que possivelmente está relacionado com o seu maior teor de carbono e maior tamanho de grão prévio, também já abordado anteriormente. Outra diferença significativa entre os aços avaliados é o tamanho de grão da austenita prévia, que é qualitativamente maior nas condições simuladas para o aço CONV do que para o aço UHHIW. O menor tamanho de grão da austenita prévia do aço UHHIW está associado à presença de precipitados de TiN homogeneamente distribuídos e coerentes com a matriz, os quais dificultam a migração dos contornos de grão devido ao efeito pinning [12,30,31] em regiões onde a temperatura de pico não supera a temperatura de sua dissolução. Para as condições de maiores velocidades de resfriamento, observa-se que a microestrutura do aço CONV é majoritariamente martensítica, figura 6, ao contrário da predominância de microconstituintes aciculares como a FWI do aço UHHIW como será comprovando nos resultados dilatométricos na, figura 7, e justificando as diferenças dos valores de dureza entre os aços, Figura 7d.

Nas figuras 7a e b são apresentadas as curvas dilatométricas dos CPs resfriados a partir de 1350 으 nas velocidades de 1,0 e $100 \circ \mathrm{C} / \mathrm{s}$, respectivamente. Em ambas as figuras é evidente a variação de comprimento ( $\Delta \mathrm{L} /$ Lo) indicando o início e término da transformação austenítica. Porém, as transformações que ocorrem em temperaturas intermediárias (PTI), como a formação dos microconstituintes FSA, FSN e FWI, são observadas mais claramente através da curva da derivada primeira de $\Delta \mathrm{L} /$ Lo em relação ao tempo $d(\Delta L / L o) / d t$.

Através da análise microestrutrual e de todas as curvas dilatométricas simuladas, foi possível criar os diagramas CCTs para a região GGZAC dos aços CONV e UHHIW, figura 7c. Na figura 7e é apresentado a sobreposição dos diagramas CCTs para facilitar a comparação desses dois aços. É possível verificar as seguintes diferenças com relação as transformações microestruturais: (i) para uma mesma velocidade de resfriamento o aço UHHIW apresenta o início de transformação em temperaturas mais elevadas que o aço $\operatorname{CONV}(\Delta T$ o FP, $\Delta T$ o P e $\Delta$ To PTI, figura 7e). Esse fenômeno pode ser explicado pelo 
menor teor de carbono e menor valor de carbono equivalente e pela provável presença de finos precipitados de TiN que atuam como inibidores do crescimento do grão austenítico favorecendo as transformações difusionais como a formação da ferritas proeutetóide (FP) e a perlita (P); (ii) no caso do aço CONV, observa-se que o campo dos produtos de transformação em temperaturas intermediarias (PTI) é maior quando comparado com o aço UHHIW. Além disso os campos de todos os microconstituintes, FP, P, PTI e, especialmente da martensita, são deslocados para maiores tempos de transformação ( $\Delta t$ FP, $\Delta \mathrm{t} P, \Delta \mathrm{t}$ PTI e, $\Delta \mathrm{t}$ M, figura 7e) e; (iii) o campo martensítico do aço CONV, em detrimento aos campos de formação da FP e da $\mathrm{P}$, é presente em praticamente todos as condições avaliadas, englobando praticamente todos os tempos de transformação, sendo dominante para condições com velocidade de resfriamento maiores que 20 ㄷ/s. Essas diferenças são em decorrência da maior temperabilidade local do aço CONV devido ao seu maior teor de carbono e maior tamanho de grão da austenita prévia quando comparado com o aço UHHIW nas mesmas condições.

Na Figura 7d é ilustrado o perfil de dureza Vickers (HV5) para todas as condições simuladas. De maneira geral, observa-se que, para os dois aços, a dureza aumenta com o aumento da velocidade de resfriamento. Essa elevação de dureza é devido à formação de microconstituintes de baixa temperatura de transformação, os quais foram favorecidos pelas elevadas velocidades de resfriamento conforme evidenciado na figura 7b. Porém, é possível verificar que o aço CONV apresenta valores de dureza superiores a $350 \mathrm{HV}$, para velocidades de resfriamento maiores que $10^{\circ} \mathrm{C} / \mathrm{s}$. O valor $350 \mathrm{HV}$ é considerado na literatura como sendo crítico para susceptibilidade à formação de trincas induzidas por hidrogênio [32]. Tal fato não é observado para o aço UHHIW, mesmo para a mais alta velocidade de resfriamento. Basicamente, essa diferença nos valores de dureza é devido à presença de microconstituintes de menor dureza em decorrência dos menores teores de carbono e valores de carbono equivalente e menor tamanho de grão da austenita prévia dos aços UHHIW.
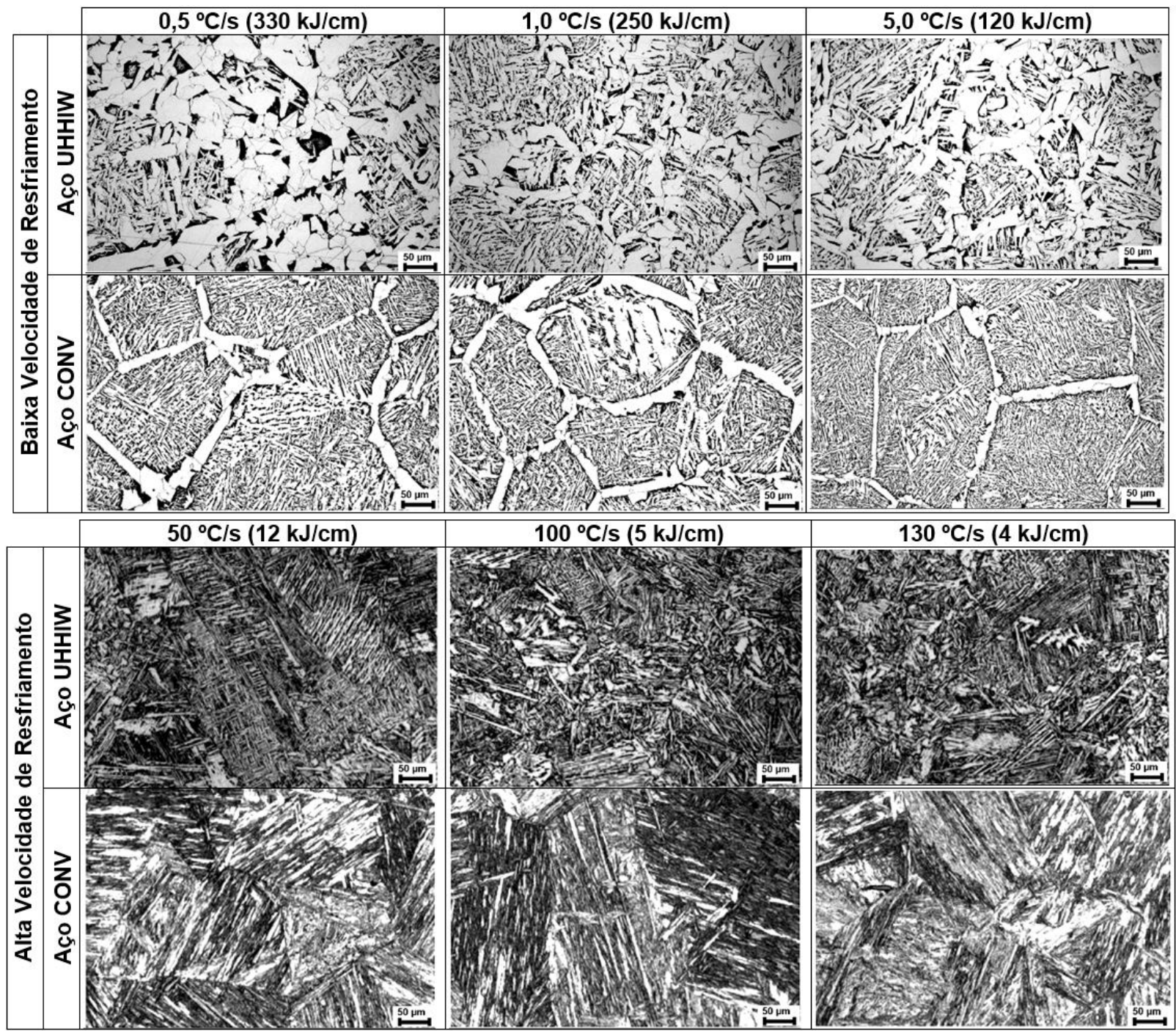

Figura 5. Microestrutura dos corpos de prova simulados nas condições de baixa e alta velocidade de resfriamento. 

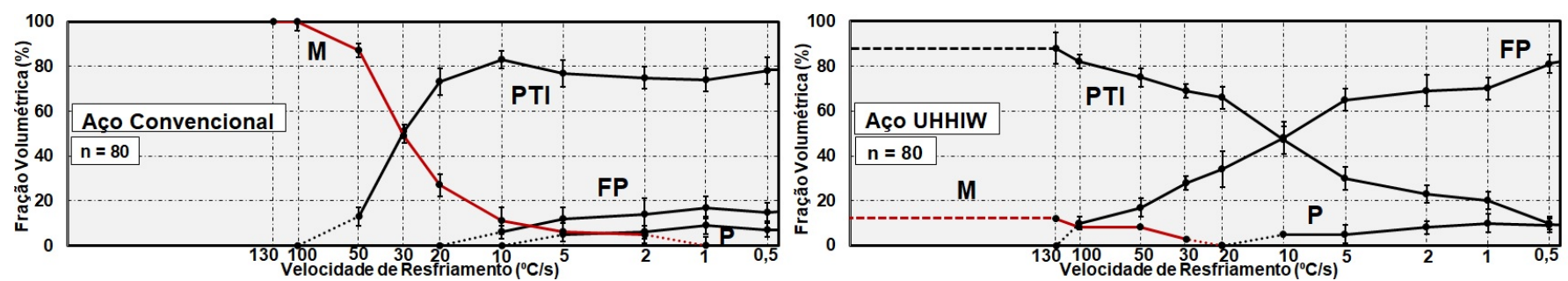

Figura 6. Distribuição dos microconstituintes observados em cada condição de resfriamento simulada no dilatômetro.
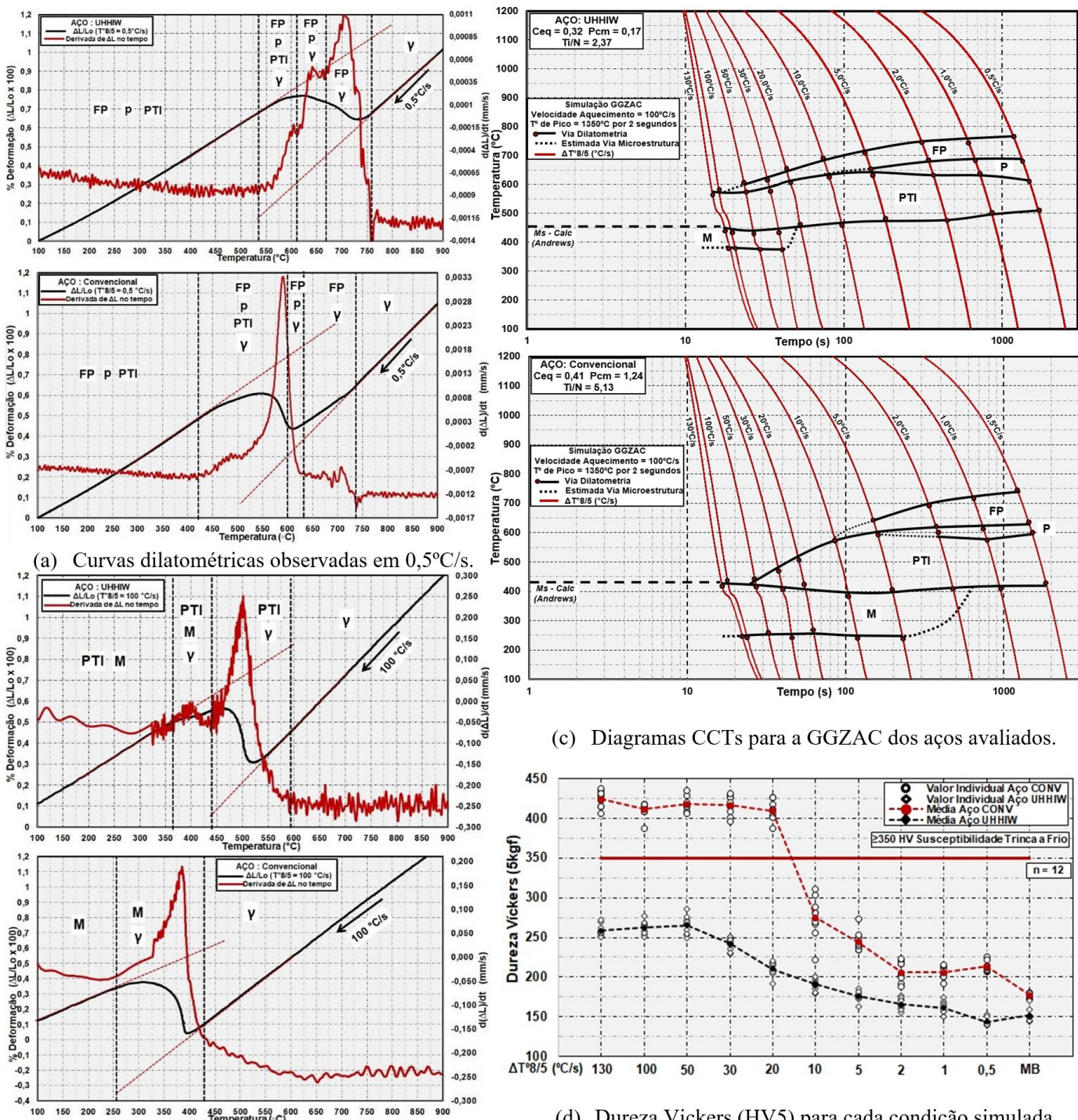

(c) Diagramas CCTs para a GGZAC dos aços avaliados.

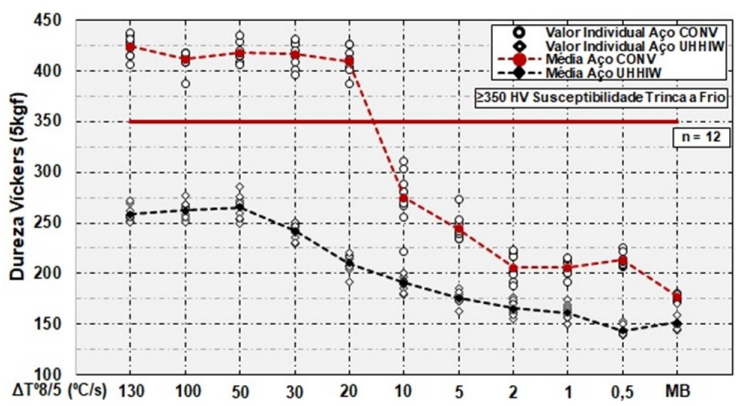

(b) Curvas dilatométricas observadas em $100^{\circ} \mathrm{C} / \mathrm{s}$.

\begin{tabular}{|c|c|}
\hline $\mathbf{F P}=$ & Ferrita proeutetóide: $\mathrm{FC} \& \mathrm{FPI}$ \\
\hline $\mathbf{P}=$ & Perlita \\
\hline $\mathbf{P T I}=$ & $\begin{array}{c}\text { Produto de transformação } \\
\text { intermediária: } \mathrm{FSA} \& \mathrm{FSN} \& \mathrm{FWI}\end{array}$ \\
\hline $\mathbf{M}=$ & Martensita \\
\hline$\Delta \mathrm{T}^{\circ} \mathbf{8} / \mathbf{5}=$ & $\begin{array}{c}\text { Velocidade de resfriamento entre } \\
800^{\circ}-500^{\circ} \mathrm{C}\end{array}$ \\
\hline $\mathbf{t} \mathbf{8 / 5}=$ & $\begin{array}{r}\text { Tempo de resfriamento entre } \\
800^{\circ} \text { - } 500^{\circ} \mathrm{C}\end{array}$ \\
\hline $\mathbf{A T}=$ & Aporte de calor simulado \\
\hline $\mathbf{Y}=$ & Austenita \\
\hline
\end{tabular}

(d) Dureza Vickers (HV5) para cada condição simulada

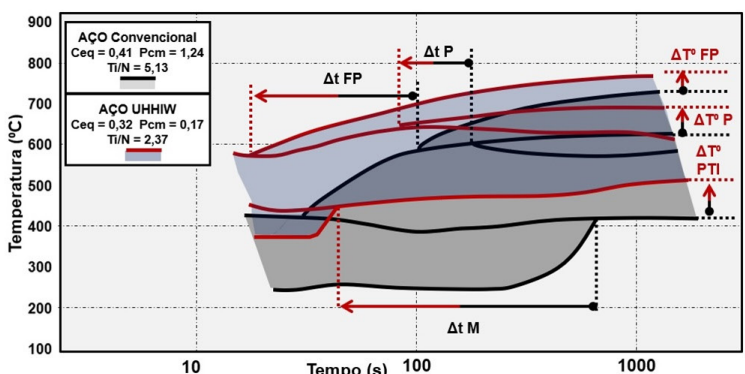

(e) Sobreposição dos diagramas CCTs da GGZAC.

Figura 7. Diagramas CCTs da região de grãos grosseiros dos aços CONV e UHHIW. 


\subsection{Simulação dos ciclos térmicos de soldagem no equipamento Gleeble ${ }^{\circledR}$}

Com o objetivo de avaliar a influência de elevados aportes de calor no crescimento de grão e, dessa forma, na tenacidade ao impacto Charpy-V, foi reproduzido, em um simulador termomecânico Gleeble ${ }^{\circledR}$, cinco réplicas da região de GGZAC aplicando o ciclo térmico de 0,5 으 $/ \mathrm{s}\left(\mathrm{AT}^{\sim} 330 \mathrm{~kJ} / \mathrm{cm}\right)$ de velocidade de resfriamento. Na Figura 8 é evidenciado o ciclo térmico simulado. É possível verificar que na região central do CP, região de interesse para avaliação da microestrutura e usinagem do entalhe para o ensaio de impacto Charpy- $V$, foi imposto com precisão (temperaturas registradas pelo termopar TC1) o ciclo térmico desejado (curva de temperatura identificada como T programado). Para avaliar a extensão da GGZAC reproduzida foram soldados um segundo (TC2) e um terceiro (TC3) termopar a 4,0 e 5,0 mm do centro do CP, respectivamente. Foi registrada uma variação de $89 \circ \mathrm{C}$ na temperatura de pico $\left(\mathrm{TC} 3=1261^{\circ} \mathrm{C}\right)$ e de $75 \circ \mathrm{C}$ na faixa de temperatura registrada entre 800 e 500 ㄷ $($ TC3 $=625$ 으) garantindo uma região central de no mínimo $10 \mathrm{~mm}$ para a realização das avaliações desejadas, visto que a GGZAC, segundo a literatura, está compreendida entre 1100 e $1450^{\circ} \mathrm{C}$ [31].
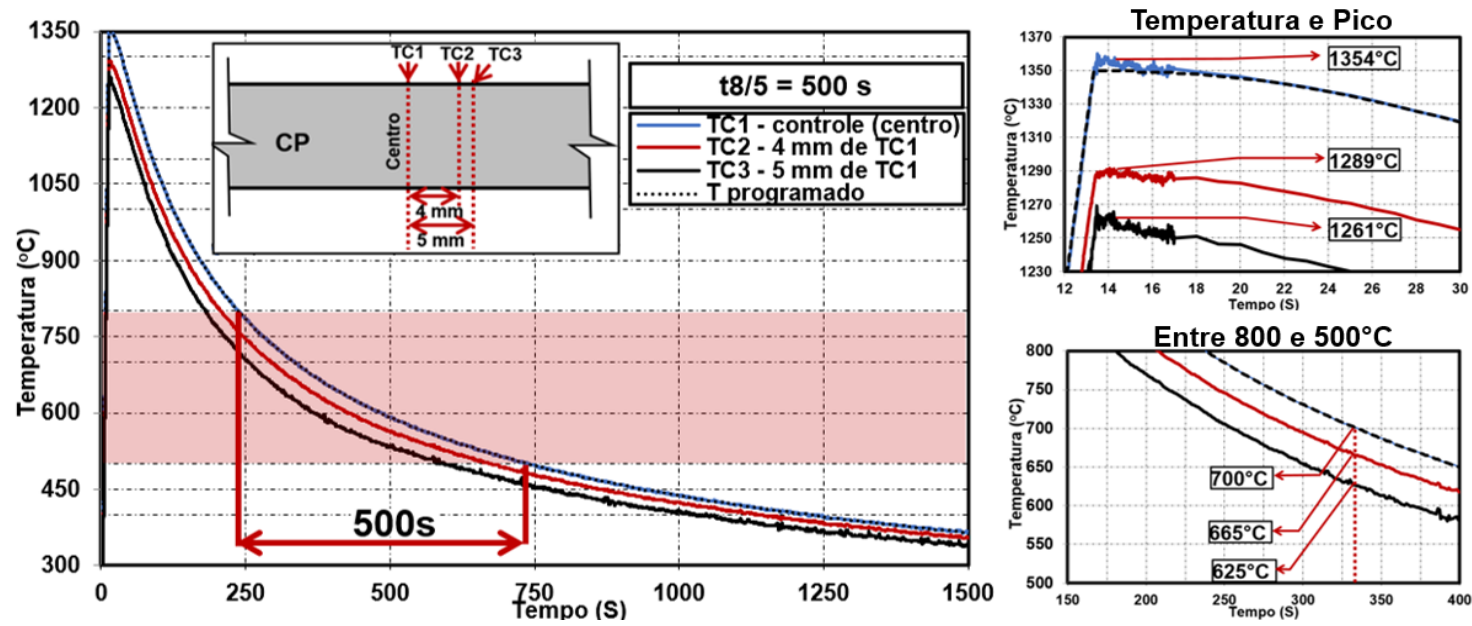

Figura 8. Variação do perfil térmico transversalmente ao corpo de prova durante a execução dos ciclos térmicos de soldagem no equipamento Gleeble ${ }^{\circledR} . \Delta \mathrm{T}^{\circ} 8 / 5=0,5^{\circ} \mathrm{C} / \mathrm{s}$.

Em uma das réplicas da GGZAC simulada na Gleeble ${ }^{\circledR}$ foi realizada análise metalográfica na seção transversal ao CP exatamente abaixo da região onde foi soldado o termopar TC1. Na Figura 9 é mostrada a microestrutura via MO após ataque com reagente nital 4\% dessa região para os dois aços avaliados. Na Tabela 5 e na Figura 10 é apresentado o resultado das frações volumétricas dos microconstituintes. É possível verificar que o aço UHHIW apresenta uma maior quantidade de FC, FPI e $\mathrm{P}$ em relação ao aço CONV, o que já era esperado conforme indicado nos resultados de dilatometria, assim como a maior fração de microconstituintes PTI formados no aço CONV. Além disso a FSA e FSN são os microconstituintes de maior fração volumétrica observados no aço CONV considerados como deletérios a tenacidade da GGZAC, especialmente quando formados em condições de elevado aporte de calor.

Observando a Figura 9 é evidente que o aço TMCP UHHIW possui TGy menor do que o aço CONV, ambos submetidos à mesma velocidade de resfriamento de $0,5 \circ \mathrm{C} / \mathrm{s}$. Para avaliar com precisão a diferença do TGү entre os dois aços foi realizada a medição da área dos mesmos em toda a seção transversal do CP. Na Figura 11 é apresentado o resultado das medições TG $\gamma$. Os dados foram analisados no software Minitab e submetidos ao teste de qualidade de ajuste de Anderson-Darling que, para valores de $p$ maiores que 0,005 , sugere para qual distribuição de probabilidade os dados se ajustam melhor [33,34]. Os gráficos de probabilidade, Figura $11 \mathrm{~b}$ e d, inclui)em pontos percentuais para as probabilidades correspondentes de um conjunto de dados ordenado. A linha do meio é o percentil esperado da distribuição com base em estimativas de parâmetros de máxima verossimilhança. As linhas esquerda e direita representam os limites inferior e superior para os intervalos de confiança de cada percentil. Para ambos os aços o TGY segue uma distribuição não parametrizada (valores $p<0,005$ para o teste de normalidade) do tipo log-normal ( $p=0,135$ para o aço UHHIW e $p=0,138$ para o aço CONV) para $95 \%$ de intervalo de confiança (IC). Na Figura 11e, é possível verificar que o aço UHHIW apresenta cerca de $79 \%$ da distribuição com áreas TG $ү$ menores que $30000 \mu \mathrm{m}^{2}$ ao contrário do aço CONV que apresentou mais da metade dos grãos medidos superiores a $60000 \mathrm{\mu m}^{2}$. 


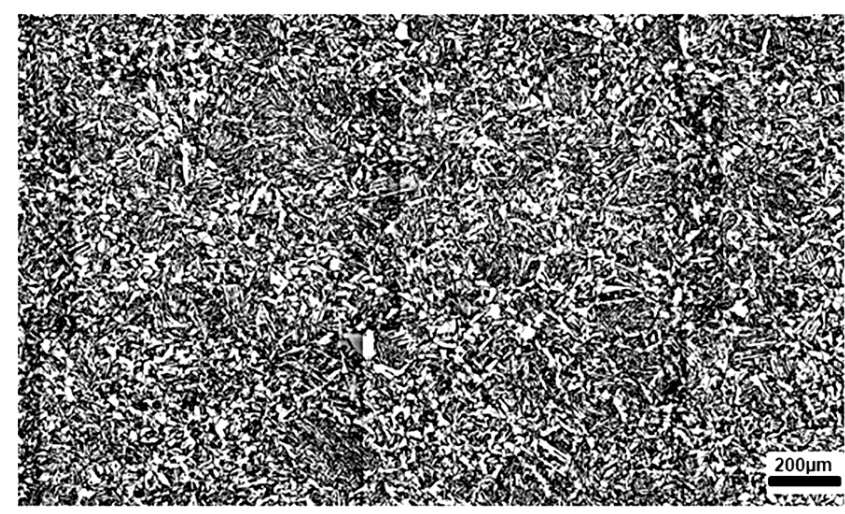

(a) Aço UHHIW.

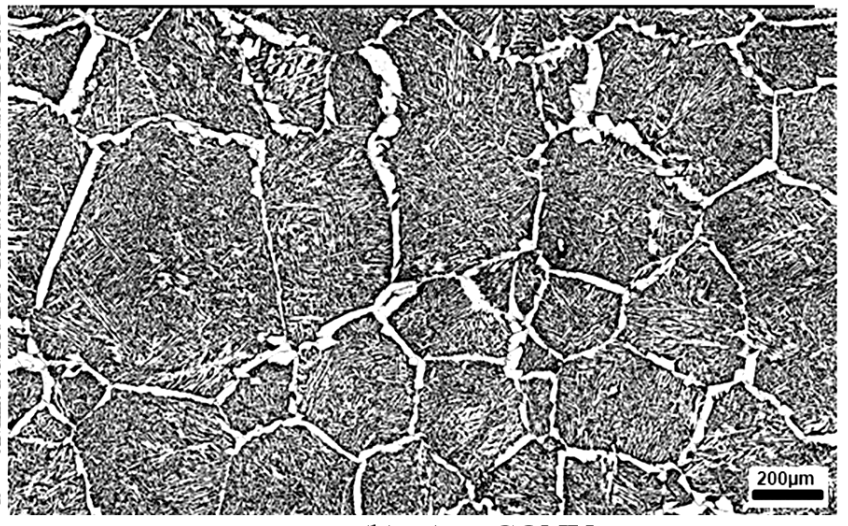

(b) Aço CONV.

Figura 9. Metalografia via MO na GGZAC simulada. Velocidade de resfriamento de $0,5 \circ \mathrm{C} / \mathrm{s}$. Ataque: Nital $4 \%$.

Tabela 5. Fração volumétrica dos microconstituintes presentes na GGZAC simulada. Intervalo de confiança $=95 \%$.

\begin{tabular}{|c|c|c|c|c|c|c|}
\hline & \multicolumn{2}{|c|}{ FP } & \multicolumn{3}{|c|}{ PTI } & \multirow{2}{*}{$\mathbf{P}$} \\
\hline & FC & FPI & WFI & FSN & FSA & \\
\hline Aço UHHIW & $25 \pm 3 \%$ & $55 \pm 3 \%$ & $0,1 \pm 0,1 \%$ & $6 \pm 1 \%$ & $6 \pm 1 \%$ & $8 \pm 1 \%$ \\
\hline Aço CONV & $14 \pm 1 \%$ & $3 \pm 1 \%$ & $12 \pm 2 \%$ & $39 \pm 2 \%$ & $30 \pm 2 \%$ & $1 \pm 1 \%$ \\
\hline
\end{tabular}

FP: Ferrita Proeutetóide; PTI = Produto de Transformação em Temperatura Intermediária; FC = Ferrita de Contorno de Grão; FPI = Ferrita Poligonal; WFI: Ferrita de Widmanstätten Intragranular; FSN: Ferrita com Segunda Fase Não Alinhada; FSA: Ferrita com Segunda Fase Alinhada; P: Perlita.
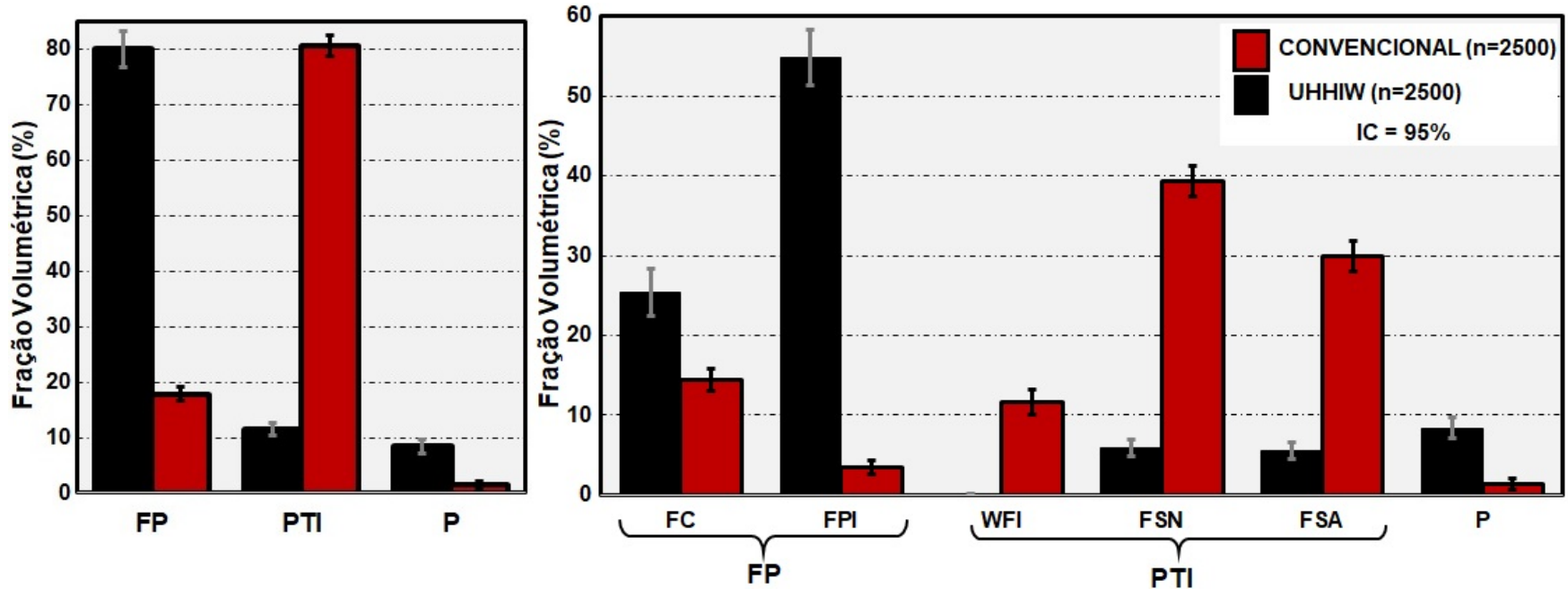

Figura 10. Fração volumétrica dos microconstituintes na GGZAC simulada. Velocidade de resfriamento de 0,5도. 


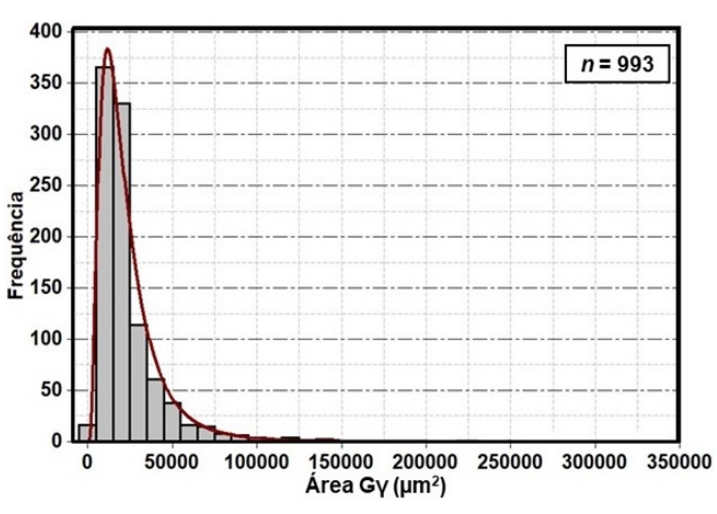

(a) Distribuição Log-normal do TG $\gamma$. Aço UHHIW.

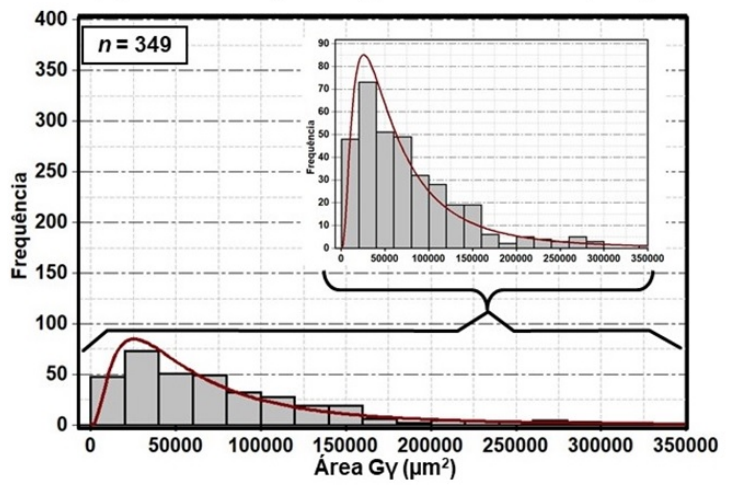

(c) Distribuição Log-normal do TG $\gamma$. Aço CONV.

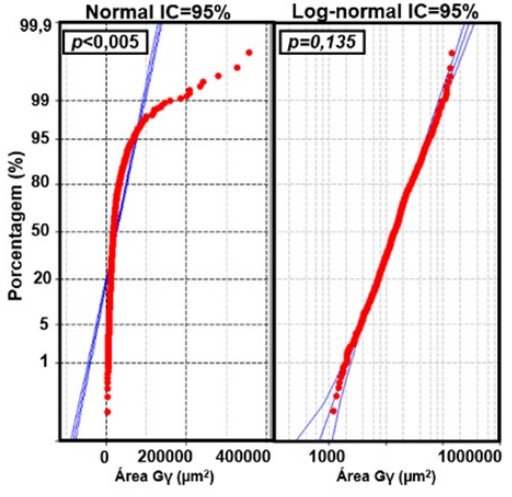

(b) Gráfico de probabilidade. Aço UHHIW.

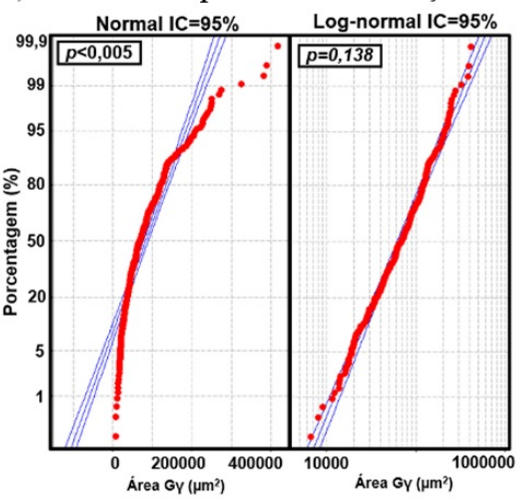

(d) Gráfico de probabilidade. Aço CONV.

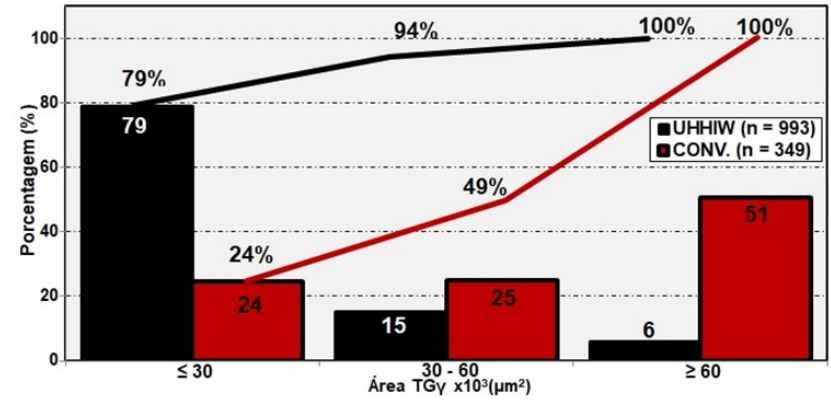

(e) Comparativo da área dos TG $\gamma$ na GGZAC para o aço UHHIW e o aço CONV.

Figura 11. Análise da área dos TGץ na GGZAC dos aços UHHIW e CONV. Velocidade de resfriamento de 0,5ㄷ/s.

Na Figura 12 são apresentados os resultados do ensaio de impacto Charpy-V. Observa-se que todos os resultados do aço UHHIW são extremamente elevados em relação aos baixos resultados obtidos para o aço CONV submetido às mesmas condições de simulação e de temperatura de ensaio. Isso se deve principalmente ao menor tamanho de grão da austenita prévia e aos menores teores de carbono e valores de carbono equivalente, que proporcionam a formação de microconstituintes de menor dureza e uma menor quantidade de segunda fase dos microconstituintes FSA e FSN. Segundo a literatura [12,35], FSA e FSN são microconstituintes frágeis, principalmente quando associados a grandes tamanhos de grãos da austenita prévia, devido aos seus contornos de baixo ângulo e não proporcionam importantes desvios na fratura, gerando facetas de clivagens planas, as quais reduzem a tenacidade do material [31,36].

Os grãos austeniticos da GGZAC, formados durante o rápido aquecimento provocado pelo ciclo térmico de soldagem, tendem a crescer afetando, dessa forma, a tenacidade da GGZAC. Basicamente, grãos austeníticos maiores provocam a redução da tenacidade devido: (i) ao favorecimento da formação de microconstituintes frágeis em função do aumento da temperabilidade local e; (ii) por não ser um obstáculo à propagação de eventuais trincas de clivagem por apresentar produtos de transformação de contornos de baixo ângulo. Sendo assim, a inibição do crescimento de grão austenítico durante a soldagem é uma boa estratégia para melhorar as propriedades a baixas temperaturas de juntas soldadas. Isso pode ser realizado através de mecanismos de ancoramento (efeito pinning) dos contornos que, geralmente, são realizados através da presença de finos precipitados coerentes e estáveis na matriz do metal base. Para as composições químicas normalmente utilizadas em aços estruturais, conforme representado na figura 13a, o método mais utilizado para refinar a microestrutura e a extensão da GGZAC, é através da adição controlada de Ti para a formação de partículas de TiN finas, coerentes e 
homogeneamente distribuídas na matriz, as quais são estáveis a elevadas temperaturas sendo, conforme ilustrado na figura $13 b$, os precipitados mais efetivos no ancoramento dos contornos de grãos da austenita [5,8]. Segundo a literatura [12,30,31] a relação Ti/N deve estar entre 2,00 e 3,4. O aço UHHIW possui uma relação Ti/N de 2,37, já o aço CONV, 5,13. Com o auxílio do software ThermoCalc ${ }^{\circledR}$, foi determinado o equilíbrio termodinâmico dos precipitados possivelmente existentes na matriz dos aços avaliados. Conforme ilustrado nas Figuras 14a e b, o aço UHHIW apresenta precipitados de TiN estáveis a partir de 1350 C justificando os menores TG observados na GGZAC simulada do aço UHHIW em relação ao aço CONV. Apesar de todos os resultados apontarem para a efetividade do efeito pinning, tal afirmativa só poderia ser confirmada através da realização de análises por microscopia eletrônica de transmissão, o que não foi feito nesse trabalho.
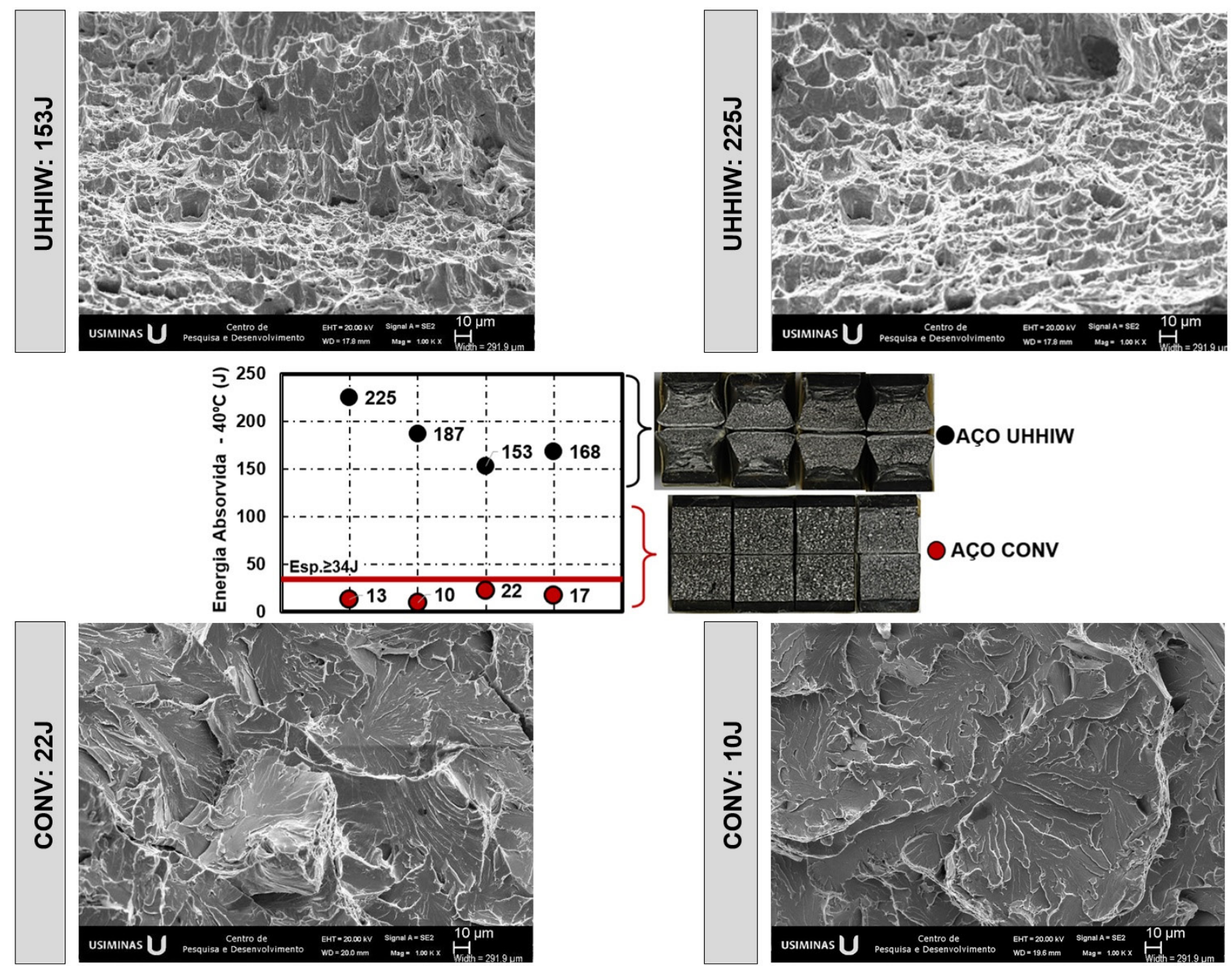

Figura 12. Resultados do ensaio de impacto Charpy-V realizado nos CPs da GGZAC simulada na Gleeble ${ }^{\circledR}$. 


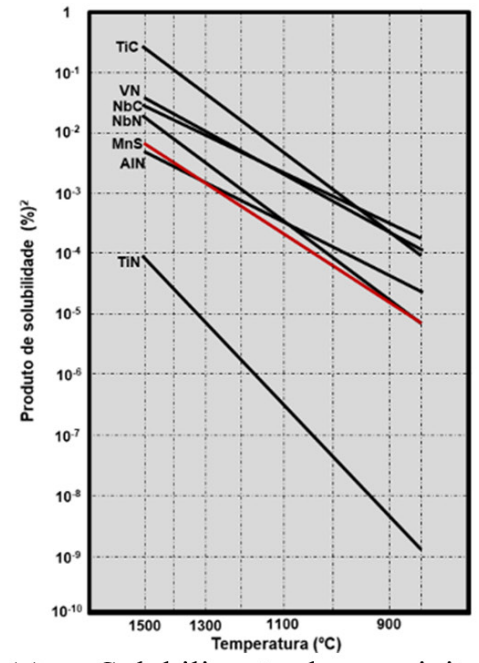

(a) Solubilização dos precipitados.
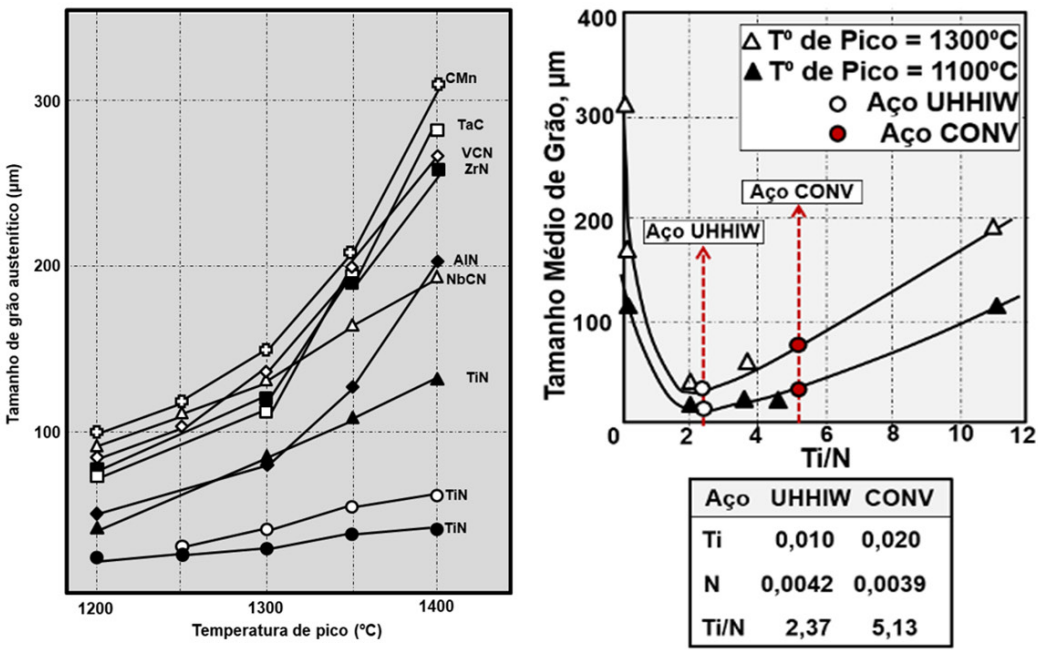

(b) TG $\gamma$ em função da presença de diferentes precipitados.

Figura 13. Ilustração da solubilização de diferentes precipitados na austenita e do tamanho de grão austenítico na GGZAC em função da presença de diferentes precipitados [30].

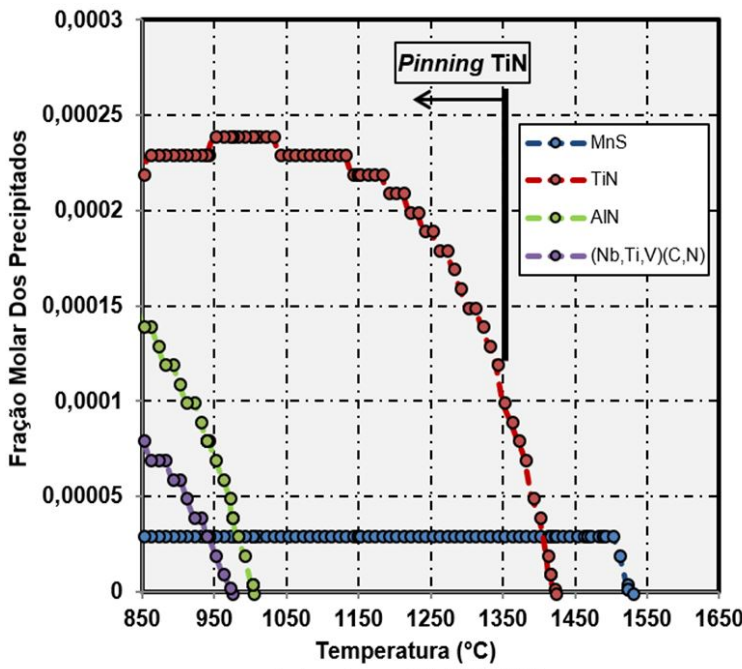

(a) Aço UHHIW.

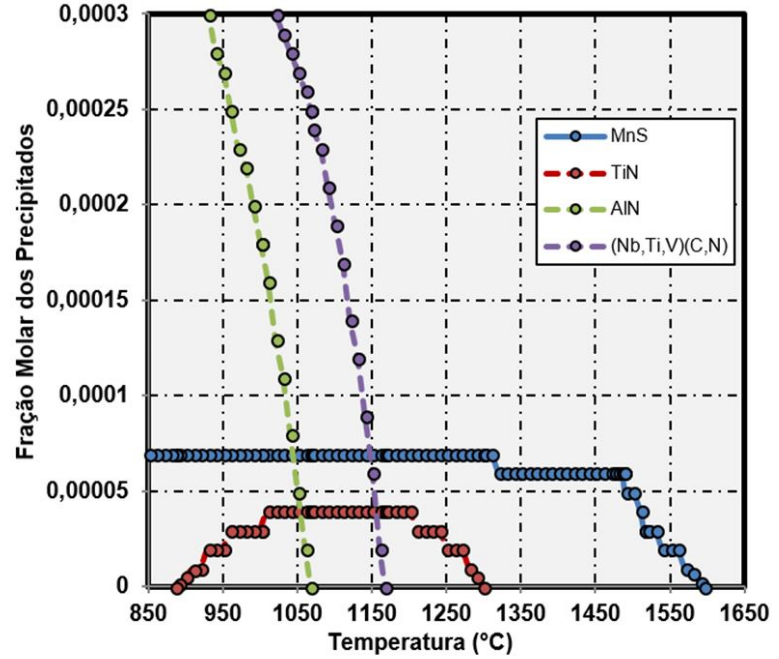

(b) Aço CONV.

Figura 14. Avaliação dos precipitados de TiN no equilíbrio termodinâmico através do software ThermoCalc ${ }^{\circledR}$.

Além do tamanho do grão austenítico, outro fator que contribuiu para os melhores resultados de tenacidade do aço UHHIW é a menor susceptibilidade à formação da microfase MA [12] devido ao seu menor teor de carbono. Segundo Ikawa [37] e Komizo [38], materiais com maiores teores de carbono quando soldados com maiores aportes térmicos possuem uma maior tendência à formação desses microconstituintes. A presença de microfases MA entre as placas dos microconstituintes FSA e FSN são pontos favoráveis para a nucleação de trincas, reduzindo a tensão de fratura do material e, dessa forma, facilitando a propagação instável da fratura [12,37,38]. Através da realização do ataque metalográfico com reagente picral seguido do metabissulfito de sódio foi possível evidenciar a microfase MA com contraste suficiente para quantificar a mesma por análise de imagens no software ImageJ, conforme mostrado na Figura 15. Na Figura 16 é evidenciado que o material CONV apresenta regiões com uma maior concentração de MA do que em outras, o que pode estar relacionado com o bandeamento microestrutural que é característico desse aço, Figura $2 \mathrm{~b}$. Regiões do metal base com a presença de perlita, durante o ciclo térmico de soldagem, rapidamente são transformadas, formando austenitas de elevado teores de carbono provocando a redução da temperatura final de transformação local. Dessa forma, após o resfriamento, são formadas regiões de austenita retida associadas a martensita caracterizando a microfase MA. Os resultados dessa análise indicam que, apesar das elevadas temperaturas atingidas na região de grãos grosseiros da ZAC, o material conserva o seu bandeamento químico, especialmente de elementos químicos substitucionais de baixa difusividade como, por exemplo, o manganês (CONV $M n=1,42 \%$; UHHIW Mn =1,38\%). O carbono (CONV C = 0,16\%; UHHIW C = 0,09\%), mesmo durante o aquecimento, se difunde 
pela austenita, mas, durante o resfriamento, tende a se concentrar nas regiões de maior temperabilidade da austenita. Essas características químicas podem explicar a heterogeneidade na distribuição do constituinte MA observada no CP do aço CONV onde a maior concentração de MA está associada a regiões com presença de colônias de perlita do metal base [39,40]. Na Figura 17 é apresentado o gráfico comparativo da fração de microfase MA entre o aço UHHIW e CONV medida em 12 campos. Como já era esperado, o aço UHHIW possui uma baixa susceptibilidade à formação desta microfase frágil, apresentando uma fração de $0,26 \pm 0,04 \%$, em comparação a $2,24 \pm 0,24 \%$ medida dentro da região bandeada do aço CONV.

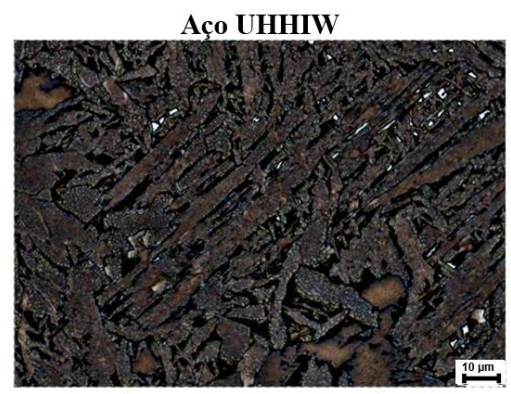

(a) Solução $1(\mathrm{t} \sim 60 \mathrm{~s})$ \& Solução $2(\mathrm{t} \sim 120 \mathrm{~s})$

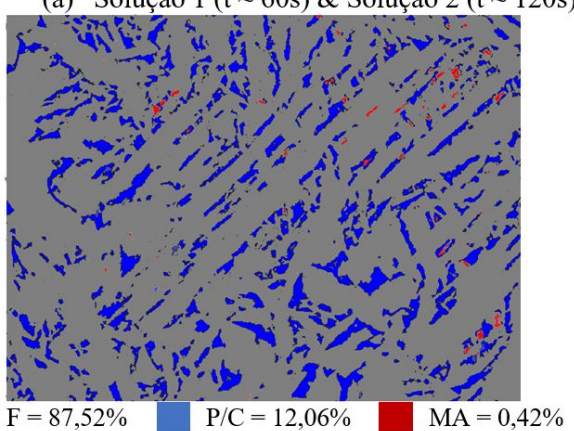

(c) Análise de imagem via software ImageJ.

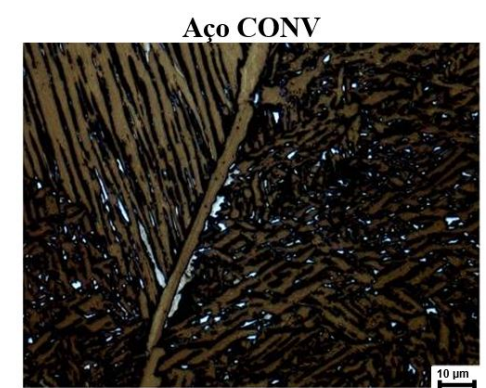

(b) Solução $1(\mathrm{t} \sim 60 \mathrm{~s})$ \& Solução $2(\mathrm{t} \sim 60 \mathrm{~s})$.

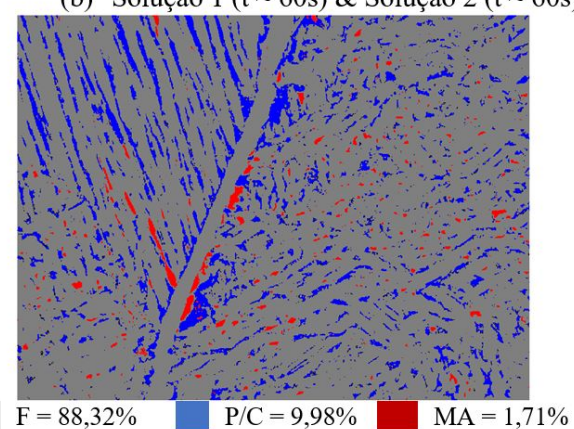

(d) Análise de imagem via software ImageJ.

Figura 15. Análise metalográfica evidenciando microfase MA na RGG dos aços UHHIW $(a, c)$ e CONV $(b, d)$. Ataque: picral (Solução 1$)$ seguido do

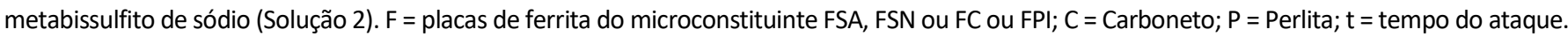
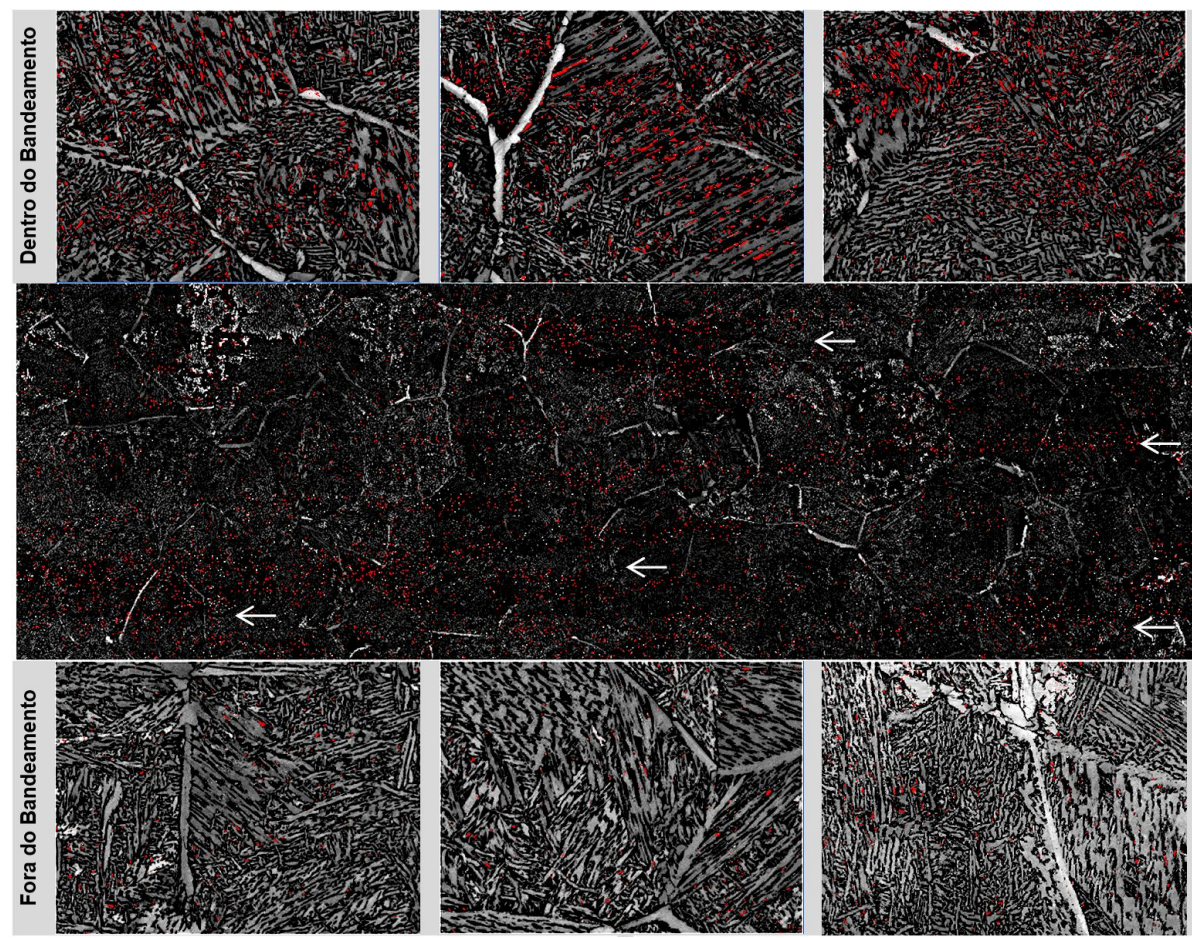

Figura 16. Análise de imagem evidenciando a maior fração de MA nas regiões bandeadas do aço CONV. As setas brancas indicam regiões com maior concentração de MA 


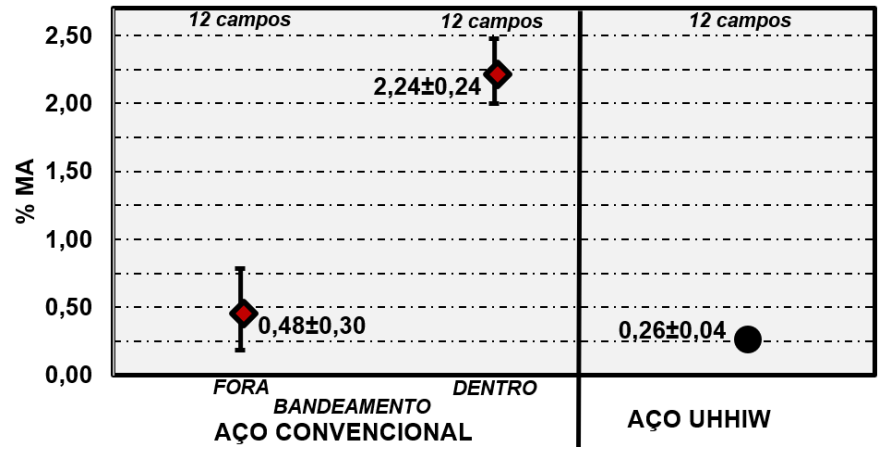

Figura 17. Fração da microfase MA GGZAC dos aços UHHIW e CONV.

\section{Conclusões}

Neste trabalho avaliou-se o desempenho de aços da classe de $355 \mathrm{MPa}$ de LE quando submetidos a ciclos térmicos reproduzindo a GGZAC de elevados aportes de calor nos simuladores termomecânicos dilatômetro e Gleeble ${ }^{\circledR}$. Os resultados das simulações físicas permitiram concluir que:

- Ensaios dilatométricos e Dureza Vickers: (i) o aço UHHIW apresenta o início de transformação em temperaturas mais elevadas que o aço CONV, favorecendo a formação das ferritas proeutetóide, o que pode ser explicado pelo menor valor de carbono equivalente e pelo menor tamanho de grão austenítico; (ii) no aço CONV, devido ao maior teor de carbono, observa-se um campo maior dos produtos de transformação em temperaturas intermediarias; (iii) o campo martensítico do aço CONV é presente em praticamente todos as condições avaliadas, sendo dominante para condições com velocidade de resfriamento maiores que $20 \circ \mathrm{C} / \mathrm{s}$; (iv) para os dois aços, foi observado o aumento da dureza com o aumento da velocidade de resfriamento devido à formação de microconstituintes de baixa temperatura de transformação. O aço CONV, no entanto, apresenta valores de dureza superiores a 350 HV5, para velocidades de resfriamento maiores que $10^{\circ} \mathrm{C} / \mathrm{s}$, considerado como sendo crítico para susceptibilidade a trincas induzidas por hidrogênio;

- Através do ataque metalográfico com reagente picral seguido do metabissulfito de sódio foi possível realizar a quantificação por análise de imagens da microfase MA. Foi evidenciado que o material CONV apresenta regiões com uma maior concentração $(2,24 \pm 0,24 \%)$ de $M A$ do que em outras $(0,48 \pm 0,30 \%)$, o que pode estar relacionado com o bandeamento microestrutural típico desse aço. Foi verificado que o aço UHHIW possui uma menor fração $(0,26 \pm 0,04 \%)$ dessa microfase frágil em comparação ao aço CONV $(2,24 \pm 0,24 \%)$;

- $\quad$ Tenacidade Charpy-V: Todos os resultados do aço UHHIW são extremamente elevados em relação aos resultados frágeis obtidos para o aço CONV submetido às mesmas condições de simulação e de temperatura de ensaio. Tal fato pode ser justificado pelo menor tamanho de grão da austenita prévia, os menores teores de carbono e valores de carbono equivalente, que proporcionam a formação de microconstituintes de menor dureza e uma menor fração da microfase MA.

- $\quad$ Pode-se concluir que a utilização dos simuladores termomecânicos dilatometro e Gleeble ${ }^{\circledR}$ são uma alternativa rápida para determinar a soldabilidade de aços estruturais. Além disso, a utilização do aço TMCP UHHIW pode ser uma excelente opção para o aumento da produtividade dos fabricantes de torres eólicas e de navios de grande porte por permitir a aplicação de processos de soldagem com elevado aporte de calor.

\section{Referências}

[1] Lloyd's Register. London: Lloyd's Register; 2017 [acesso em 30 out. de 2017. Disponível em: http://www.Ir.org/about_us/

[2] Imai S. Recent progress and future trends for shipbuilding steel. Welding International. 2008;22(11):755-761. http://dx.doi.org/10.1080/09507110802550661.

[3] Abeeolica. [página da internet]. São Paulo: Abeeólica; 2019 Acesso em 09 jan. 2019. Disponível em: http://www.portalabeeolica.org.br

[4] Domingues JR. Panorama da Tecnologia da Soldagem na Indústria Naval/Offshore no Brasil Cenário Atual e Tendências. In: Sindicato Nacional da Indústria da Construção e Reparação Naval e Offshore. Anais da 4o Feira e Conferência da Indústria Naval e Offshore NAVALSHORE; 2009; Rio de Janeiro. Rio de Janeiro: NavalShore; 2009. p. 116-127.

[5] Borba TMD, et al. Avaliação da Soldabilidade do Aço Sincron EN 10025-4 S355M aplicado na fabricação de torres eólicas com processo de 
soldagem de alta deposição. Soldagem \& Inspeção. 2017;22(4):413-428.

[6] Sindicato Nacional da Indústria da Construção e Reparação Naval e Offshore - SINAVAL. [página da internet]. Rio de Janeiro: SINAVAL; 2019 [acesso em 09 jan. 2019]. Disponível em: http://sinaval.org.br/

[7] Agência Nacional de Energia Elétrica - ANEEL. Programa de Incentivo às Fontes Alternativas - Proinfa. Brasília: ANEEL; 2018 [acesso em 16 maio de 2018] Disponível em: http://www.aneel.gov.br/proinfa

[8] Borba TMD, et al. Assessment of the Weldability of EH36 TMCP Shipbuilding Steel Welded by High Heat Input Submerged Arc Welding. Welding International. 2016;31(3):184-195. http://dx.doi.org/10.1080/09507116.2016.1218619.

[9] Silva RF. Caracterização da zona termicamente afetada de aço produzido via resfriamento acelerado [dissertação de mestrado]. Belo Horizonte: PPGEM/UFMG; 2010.

[10] Amaral TS. Atlas microestrutural para otimização de procedimentos de soldagem. Uberlândia: POSMEC/UFU; 2016.

[11] Scotti A, et al. Um Round-Robin Teste com Simulação Térmica da ZAC de Soldagem para Obtenção de Diagramas CRC: a necessidade de procedimentos e terminologia de microconstituintes harmonizados. Soldagem e Inspeção. 2014;19(3):279-290. http://dx.doi.org/10.1590/0104-9224/SI1903.11.

[12] Alé RM. Efeito da adição de elementos de liga ( $\mathrm{Cu}$ e Ni) nas propriedades mecânicas e microestrutura da ZAC de Aços C-Mn Microligados ao Nb. [tese de doutorado]. Rio de Janeiro: UFRJ; 1994. $142 \mathrm{f}$.

[13]Deutsches Institut für Normung. DIN EN 10025-2: Hot Rolled Products of Structural Steels Part 2: Technical Delivery Conditions for NonAlloy Structural Steels. Berlin: DIN; 2005.

[14]Deutsches Institut für Normung. DIN EN 10025-4: Hot Rolled Products of Structural Steels Part 2: Technical Delivery Conditions for Thermomechanical Rolled Weldable Fine Grain Structural Steels. Berlin: DIN; 2005.

[15] American Society for Testing and Materials. ASTM E112: Test methods for determination average grain size. West Conshohocken: ASTM; 1996.

[16]American Society for Testing and Materials. ASTM A370: Test methods and definitions for mechanical testing of steel products. West Conshohocken: ASTM; 2008. Revisão A. Versão anterior: 2007.

[17] Rykalin R. Energy sources for welding. Welding in the World. 1974;12(9-10):227-248.

[18] Vimalan G, Ravichandran G, Muthupandi V. Phase transformation behaviour in P91 during post weld heat treatment: a gleeble study. Transactions of the Indian Institute of Metals. 2017;70(3):875-885. http://dx.doi.org/10.1007/s12666-017-1075-0.

[19] Huang Q, Volkova O, Biermann H, Mola J. Dilatometry analysis of dissolution of Cr-rich carbides in martensitic stainless steels. Metallurgical and Materials Transactions. A, Physical Metallurgy and Materials Science. 2017;48(12):5771-5777. http://dx.doi.org/10.1007/s11661-017-4377-2.

[20] Shahriari B, Vafaei R, Sharifi EM, Farmanesh K. Contínuous cooling transformation behavior and the kinetics of bainite formation in a bainitic-martensitic steel. International Journal of Materials Research. 2017;108(9):715-724. http://dx.doi.org/10.3139/146.111531.

[21] Lopez-Martinez E, Vázquez-Gómez O, Vergara-Hernández HJ, Campillo B. Effect of initial microstructure on austenite formation kinetics in high-strength experimental microalloyed steels. International Journal of Minerals Metallurgy and Materials. 2015;22(12):1304-1312. http://dx.doi.org/10.1007/s12613-015-1198-4.

[22] The Welding Institute. Introductory Notes on Metallography of Welds in C-Mn Steels. Reino Unido: TWI; 1984. 36 p.

[23] American Society for Testing and Materials. ASTM E562-89: standard test method for determining volume fraction by systematic manual point count. Philadelphia: Annual Book of ASTM Standards; 1989. p. 502-507.

[24] Kong X, Lan L, Hu Z, Li B, Sui T. Optimization of Mechanical Properties of High Strength Bainitic Steel Using Thermo-Mechanical and Accelerated Cooling Process. Journal of Materials Processing Technology, China. 2015;217:202-210. http://dx.doi.org/10.1016/j.jmatprotec.2014.11.016.

[25] Hall EO. The Deformation and Ageing of Mild steel: III Discussion of Results. Proceedings of the Physical Society. 1951;64(9):747-753.

[26] De Meester B. Note on the carbon equivalent. Welding in the World. 1990;28(3/4):8-11.

[27] Caballero FG, Capdevila C, De Andrés CG. Modelling of kinetics and dilatometric behaviour of austenite formation in a low-carbon steel with a ferrite plus pearlite initial microstructure. Journal of Materials Science. 2002;37(16):3533-3540. http://dx.doi.org/10.1023/A:1016579510723.

[28] Lee S-J, Clarke KD, Van Tyne CJ. A on-heating dilation conversional model for austenite formation in hypoeutectoid steels. Metallurgical and Materials Transactions. 2010;41(9):2224-2235.

[29] Savran VI, Offerman SE, Sietsma J. Austenite nucleation and growth observed on the level of individual grain by three-dimensional X-ray diffraction microscopy. Metallurgical and Materials Transactions. 2010;41A:583-591.

[30] Kanazawa S. Improvement of weld fusion zone toughness by fine TiN. Transactions ISIJ. 1976;16. 
[31] Easterling K. Introduction to the Physical metallurgy of Welding. Londres: BMM; 1983. 231 p.

[32] De Meester B. The weldability of modern structural TMCP Steel. ISIJ International. 1997;37(6):537-551.

[33] Anderson TW, Darling DA. Asymptotic theory of certain "goodness-of-fit" criteria based on stochastic processes. Annals of Mathematical Statistics. 1952;23(2):193-212. http://dx.doi.org/10.1214/aoms/1177729437.

[34] Razali N, Wah Y. Power comparisons of Shapiro-Wilk, Kolmogorov-Smirnov, Lilliefors and Anderson-Darling tests. Journal of Statistical Modeling and Analytics. 2011;2(1):21-33.

[35] Batte AD, Kirkwood PR. Developments in the Weldability and toughness of Steels for Offshore Structure. In: American Society of Mechanical Engineers. Proceedings of the 88th International Conference on Microalloying; 1988; EUA. EUA: ASME; 1988. p. $175-188$.

[36] Alé RM, et al. Soldagem de Aços de Alta Resistência Produzidos via Resfriamento Acelerado. In: Associação Brasileira de Metalurgia e Materiais. Anais do 65 Congresso da Associação Brasileira de Metalurgia e Materiais; 2010; Brasil. Brasil: ABM; 2010.

[37] Ikawa H, et al. Effect of MA Constituent on HAZ Toughness of a High Strength Steel. Journal of the Japan Welding Society. 1980;49(8):532-537.

[38] Komizo YI, Fukado Y. CTOD Properties and MA Constituent in HAZ of C-Mn Microalloyed Steel. Quarterly Journal of the Japan Welding Society. 1986;4(2):447-452.

[39] Akselsen OM, Solberg, J.K., Grong, O. Effects of martensite-austenite (MA) islands on intercritical heat-affected zone toughness of low carbon miroalloyed steels. Scandinavian Journal of Metallurgy. 1988;17:194-200.

[40] Akselsen OM, Grong O, Solberg JK. Structure-property relationships in intercritical heat affected zone of low-carbon microalloyed steels. Materials Science and Technology. 1987;3:649-655. http://dx.doi.org/10.1179/mst.1987.3.8.649. 